\title{
SIMULAÇÃO MATEMÁTICA DO PROCESSO DE TRANSFORMAÇÃO DE CHUVA EM VAZÃO: ESTUDO DO MODELO TOPMODEL
}

\author{
Renato F. Varella \\ Universidade do Estado de Mato Grosso - UNEMAT \\ Campus Universitário de Nova Xavantina - CEP 78690-000 N. Xavantina, MT \\ varella@unb.br
}

Néstor A. Campana

Dpto. de Engenharia Civil - Faculdade de Tecnologia - UnB

Campus Universitário, Asa Norte - CEP 70910-900 Brasília, DF mnestor@unb.br

\section{RESUMO}

O TOPMODEL (Topography Based Hydrological Model), Beven et al. (1994), é um modelo de transformação de chuva em vazão do tipo conceitual e semi-distribuído que considera área variável de contribuição à formação de escoamento superficial. Os fatores que determinam o surgimento do escoamento superficial são representados pela topografia do terreno e por uma lei exponencial que relaciona a transmissividade com a profundidade do solo, medida a partir de sua superfície.

A influência da topografia da bacia na geração de escoamento superficial é considerada, no modelo, através do índice topográfico, calculado a partir do modelo digital de elevações. Este estudo, concentra-se principalmente na análise da influência da resolução do modelo numérico do terreno sobre o desempenho do modelo. Para tanto foi selecionada uma bacia, localizada no Distrito Federal, Brasil, para a qual foram elaborados sete modelos numéricos do terreno, com resoluções espaciais de 30,60, 90, 120, 150, 180 e 210 m. A partir destes modelos numéricos do terreno, gerouse diversas distribuições de índice topográfico.

Na primeira parte deste trabalho são apresentados os resultados da calibração do modelo e análise de sensibilidade dos diversos parâmetros, identificando aqueles que mais influenciam no seu desempenho.

Na segunda parte são apresentados os resultados da aplicação do modelo, dando-se ênfase às condições que devem ser observadas para se obter um bom resultado.

\section{DESCRIÇÃO DO TOPMODEL}

O modelo possibilita o cálculo da vazão, numa determinada seção de um rio, considerando a bacia como um todo ou subdividindo-a em várias sub-bacias. Os valores de precipitação e evapo- transpiração potencial, as entradas do modelo, são considerados homogêneos em toda a bacia, isto é, assume-se um valor médio. As hipóteses básicas utilizadas no desenvolvimento do modelo, são descritas por Beven et al. (1994):

- A dinâmica da zona saturada pode ser representada através de estados estacionários sucessivos;

- O gradiente hidráulico na zona saturada pode ser representado pela declividade da superfície do terreno no local, $\tan \beta_{\mathrm{i}}\left(\beta_{\mathrm{i}}\right.$, ângulo formado entre o plano da superfície do solo e o plano horizontal, a declividade).

Esta última hipótese é incorporada no modelo na forma de um índice, denominado de índice topográfico de Kirkby e Beven, $\ln \left(a / \tan \beta_{\mathrm{i}}\right)$, onde a representa a área de drenagem por unidade de comprimento da curva de nível cruzada pelo escoamento. Este índice, inicialmente proposto por Kirkby (1975), representa a propensão de qualquer local da bacia de desenvolver condições de saturação.

A Figura 1 esquematiza a formação de escoamento superficial através da área de contribuição, segundo a qual são desenvolvidas as equações do modelo.

O fluxo $\mathrm{q}_{\mathrm{i}}$, que ocorre num local qualquer da bacia na zona saturada, depende da declividade do terreno e da transmissividade lateral.

Considerando que o gradiente hidráulico efetivo e o fluxo na zona saturada são paralelos à declividade do terreno, caracterizada por $\tan \beta_{\mathrm{i}}$, pode-se escrever, para qualquer ponto i da encosta, o fluxo que ocorre na zona saturada:

$$
\mathrm{q}_{\mathrm{i}}=\mathrm{T}_{\mathrm{i}} \cdot \tan \beta_{\mathrm{i}}
$$

onde $q_{i}$ representa o fluxo por unidade de comprimento; $T_{i}$ a transmissividade no ponto $i$ na profun- 


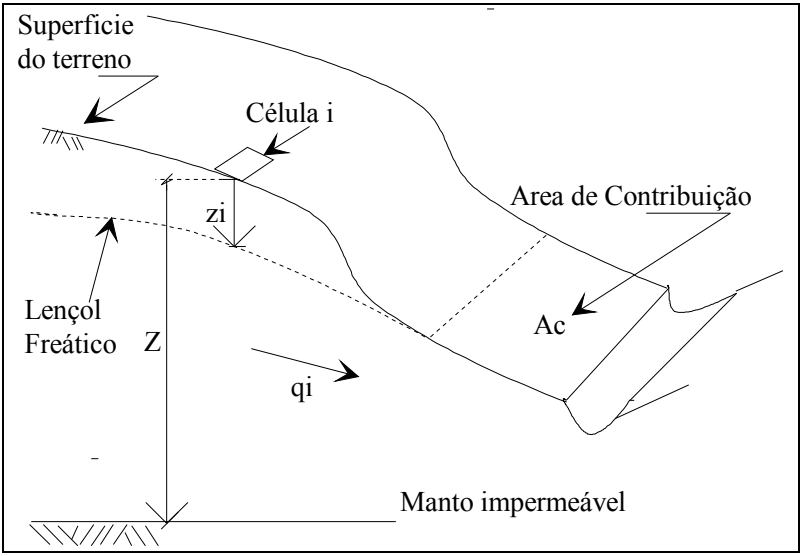

Figura 1. Formação de escoamento superficial - conceitualização do TOPMODEL (fonte: adaptado de Franchini et al., 1996).

didade $z_{i}$ e $\beta_{i}$ a declividade do terreno. A contribuição total da zona saturada à vazão, medida na seção de saída da bacia, é obtida fazendo-se a somatória das contribuições individuais, $\mathrm{q}_{\mathrm{i}}$.

O cálculo da transmissividade nos diversos pontos da bacia é fundamentado no trabalho de Beven (1984), que apresentou dados experimentais indicando um declínio exponencial da condutividade hidráulica do solo (vertical) com a profundidade e no fato que este modelo seria adequado para descrever as mudanças nas propriedades hidráulicas, na direção vertical, para uma grande variedade de solos. Beven (1986) mostrou, também, que uma função exponencial equivalente para a transmissividade podia ser deduzida, assumindo-se isotropia:

$$
T_{i}=T_{0} \cdot e^{-S_{i} / m}
$$

onde $\mathrm{T}_{0}$ representa a transmissividade lateral quando o solo está saturado; $S_{i}$ é o déficit de armazenamento no local i; e m parâmetro do modelo. Esta equação é bastante importante, pois nela estão incluídos os principais parâmetros do modelo, $\mathrm{T}_{0}$ e $\mathrm{m}$.

O parâmetro m (parâmetro de decaimento da transmissividade), valor único para toda a bacia, é interpretado fisicamente como aquele que expressa a profundidade real do perfil de umidade do solo da bacia, atuando interativamente com $\mathrm{T}_{0}$. Um valor grande de $\mathrm{m}$ determina, efetivamente, uma maior profundidade do perfil de umidade do solo. Por outro lado, valores pequenos deste parâmetro, especialmente combinados com valores altos de $T_{0}$, resultam em perfis de umidade rasos com decaimento bastante pronunciado da transmissividade.
Um terceiro parâmetro do TOPMODEL é a capacidade máxima de armazenamento de água na zona das raízes que é descrita como um reservatório de capacidade máxima potencial $S_{r \max }$. Este parâmetro é utilizado na determinação da evapotranspiração real que é calculada no modelo como uma função da evapotranspiração potencial e da quantidade de água armazenada na zona das raízes. O modelo considera que a evaporação se dá com valor igual à evaporação potencial para áreas onde está ocorrendo drenagem gravitacional e, nos locais, onde a superfície do solo atingiu a saturação. Quando cessa a drenagem gravitacional, a evapotranspiração continua sendo calculada por:

$$
E_{a}=E_{p} \cdot\left(1-\frac{S_{r z}}{S_{r \max }}\right)
$$

onde $E_{a}$ é a evapotranspiração real; $E_{p}$ a evapotranspiração potencial; $S_{y z} 0$ déficit na zona das raízes e $S_{r \max }$ o máximo déficit possível na zona das raízes.

A conceitulização do fluxo de água no solo é estruturada na forma de armazenamentos, estando incluídos os conceitos de ponto de murchamento e de capacidade de campo segundo o esquema, mostrado na Figura 2.

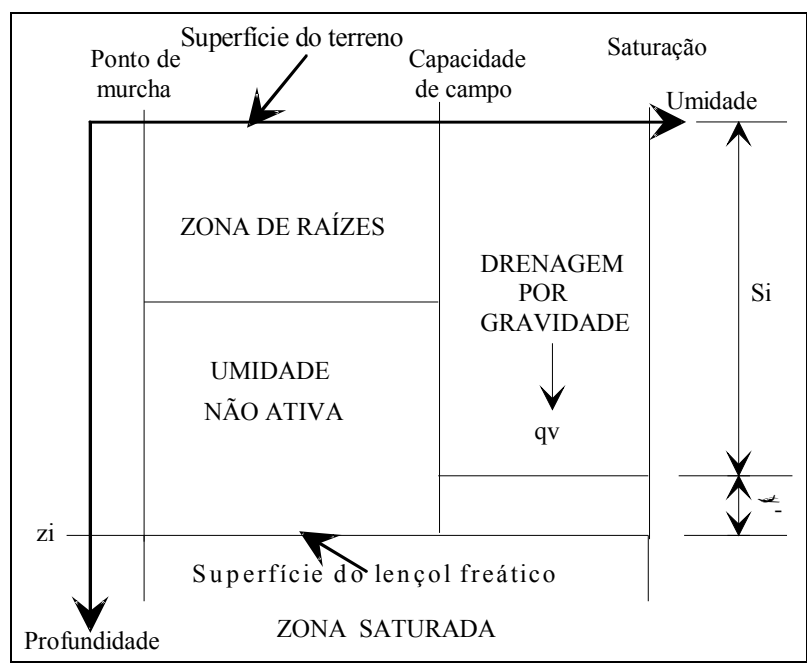

Figura 2. Esquema simplificado dos armazenamentos no TOPMODEL (fonte: adaptado de Beven et al., 1994).

Este conceito, de capacidade de campo significa o valor de umidade que deve ser atingido antes que ocorra fluxo gravitacional para a zona saturada, foi introduzido no modelo para criar um retardo no fluxo vertical na zona não saturada até a 
zona saturada. Desta maneira, há uma maior retenção da água infiltrada, antes que ela possa entrar na zona saturada, permanecendo disponível ao processo de evapotranspiração, reduzindo os valores estimados de vazão, em especial quando ocorrem precipitações intensas logo após períodos de seca.

Partindo-se destas hipóteses básicas e da Equação (2), que descreve quantitativamente o decaimento da transmissividade do solo com a profundidade, pode-se deduzir as demais equações necessárias ao cálculo da quantidade de água infiltrada, da recarga do lençol freático e sua profundidade, do escoamento superficial e da umidade do solo na zona não saturada. O desenvolvimento destas equações é apresentado no trabalho de Mine \& Clarke (1996), que fizeram uma aplicação do TOPMODEL à bacia do rio Belém, que drena uma área de $42 \mathrm{~km}^{2}$, constituída quase que inteiramente por área urbanizada, localizada na cidade de Curitiba, no estado do Paraná.

\section{DESCRIÇÃO DA ÁREA DE ESTUDO}

A área de estudo, compreende a região da bacia do Rio Descoberto, à montante do Lago do mesmo nome, tendo a maioria de sua superfície no Distrito Federal e uma pequena parte no estado de Goiás. Localiza-se, conforme mostra a Figura 3, entre os paralelos de $15^{\circ} 36^{\prime} 15^{\prime \prime}$ e $15^{\circ} 44^{\prime} 30^{\prime \prime}$ de latitude Sul e entre os meridianos de $48^{\circ} 07^{\prime} 30^{\prime \prime}$ e $48^{\circ} 16^{\prime} 30^{\prime \prime}$ de longitude Oeste. A área total de drenagem da bacia do Rio Descoberto é de aproximadamente $114 \mathrm{~km}^{2}$. Dispõe em sua seção de saída de uma estação fluviográfica chamada de Descoberto Montante, cadastrada no DNAAE com o código 60435000 que é constituída por um linígrafo e régua linimétrica, da qual os dados de vazão foram obtidos.

$\mathrm{Na}$ área da bacia existe uma estação pluviográfica, Brazlândia (código DNAAE 01548007) que forneceu dados de precipitação para o ano de 1995. Localizadas fora da área de drenagem, mas próximas à mesma, existem mais 4 estações, das quais a estação Descoberto Jusante (código DNAAE 01548008) também dispõe de registrador e forneceu os dados de precipitação referentes ao ano de 1988. Para as demais estações, Taguatinga, Fazenda Santa Elisa e Jatobazinho (ver Figura 3) dispunha-se de totais diários de precipitação para esses dois anos. Estes dados foram empregados na distribuição espacial da precipitação. Embora exista uma estação climatológica na bacia do Rio Descoberto, não se dispunha de dados de evapotranspiração para as épocas estudadas e por isso foram usadas informações sobre evaporação obtidas na estação da UnB.

\section{ESTRUTURA DO TRABALHO}

A esquematização das atividades abrangendo a preparação das informações necessárias à operação do modelo (fornecidas na forma de arquivos de dados) e as técnicas envolvidas, são apresentadas na Figura 4.

Operacionalmente, os dados de entrada do TOPMODEL são fornecidos através de 3 arquivos: o primeiro contém os valores de todos os parâmetros; o segundo a distribuição de índice topográfico e informações de áreas de drenagem acumuladas em função das distâncias até a seção de saída da bacia e o último, informa ao modelo a quantidade total de intervalos de tempo a serem processados; o valor do passo de tempo e valores de vazão, precipitação e de evapotranspiração. Os valores de precipitação foram provenientes da estação pluviográfica do Descoberto (DNAAE - 01548008) para o ano de 1988 e Brazlândia (DNAAE - 01548007) para 1995, que eram as únicas estações que dispunham de dados horários.

Os dados de vazão foram obtidos de linigramas da única estação com registrador disponível na área de estudo, localizada na seção de saída da bacia. Estes valores abrangem o período de 11 de fevereiro (iniciando às 8:00 horas) a 21 de março de 1988 perfazendo um total de 920 horas ininterruptas.

O modelo requer, também, valores de evapotranspiração potencial para fazer o balanço de água a cada intervalo de tempo. Como não se dispunha, para a área da bacia, de dados de evaporação, para se fazer o cálculo da evapotranspiração foram utilizadas medidas de evaporação em tanque classe $A$ obtidas na estação da UnB localizada às margens do Lago Paranoá. Assumiuse que, a taxa de evaporação diária na área em estudo é a mesma que a desta estação.

$\mathrm{Na}$ formulação do modelo, a topografia do terreno é bastante importante, sendo fornecida ao modelo na forma do índice topográfico de Kirkby e Beven, $\ln (a / \tan \beta)$. Os valores de partida dos parâmetros foram obtidos a partir de informações bibliográficas sobre aplicações do TOPMODEL a outras bacias.

O cálculo da distribuição dos valores desse índice na bacia, foi feito por um programa, GRIDATB, que utiliza técnica de análise de modelo numérico do terreno, MNT descrita por Quinn et al. (1991), fornecido juntamente com o TOPMODEL. Foram utilizados mapas topográficos em formato 


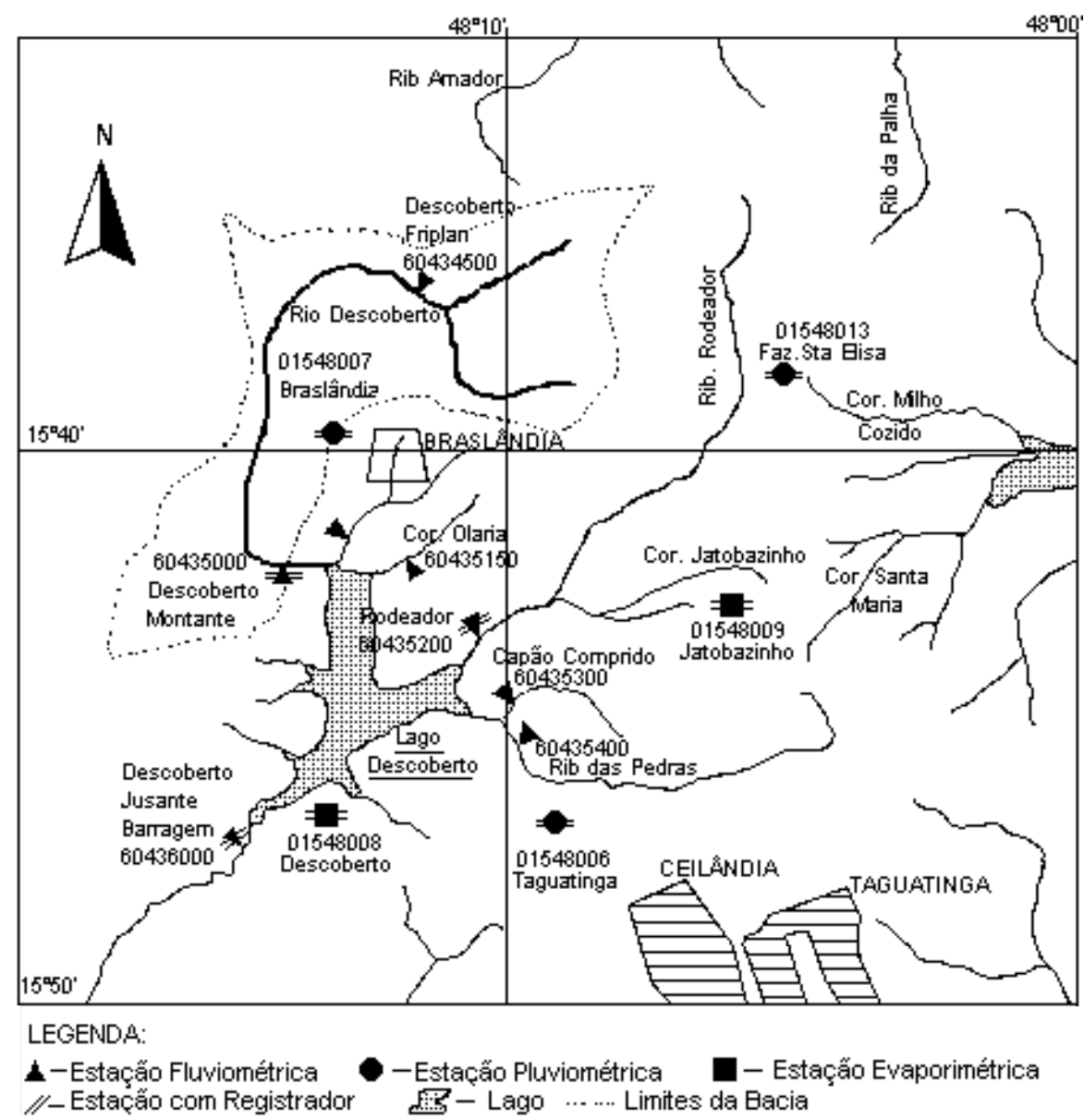

Figura 3. Estações hidrometeorológicas existentes na área de estudo. Fonte: CAESB - DF

digital, que distribuídos espacialmente por Kriging, produziram o MNT.

\section{PARÂMETROS DO MODELO}

A versão utilizada neste trabalho, 94.01, utiliza 10 parâmetros, que são fornecidos ao modelo por um arquivo que inclui também, o valor da vazão do rio para tempo igual a zero, e um valor (1 ou 0) armazenado na variável chamada INFEX, que solicita ao programa o acionamento do módulo de cálculo de escoamento superficial por excesso de infiltração. Os parâmetros do modelo são os seguintes:

\footnotetext{
$\mathrm{m}$ = Parâmetro de decréscimo exponencial da transmissividade;
}

$\mathrm{T}_{0}=$ Transmissividade lateral quando o solo está saturado;

$t_{d}=$ Tempo de permanência na zona não saturada por unidade de déficit;

$\mathrm{CHV}=$ Velocidade de propagação no canal principal;

$\mathrm{RV}=$ Velocidade nas sub-bacias;

$\mathrm{S}_{\mathrm{rmax}}=$ Máximo déficit possível na zona das raízes;

$\mathrm{S}_{\mathrm{r} 0}=$ Déficit inicial na zona das raízes;

$\mathrm{K}_{0}=$ Condutividade hidráulica de saturação da superfície do solo;

$\mathrm{HF}=$ Valor de sucção na frente de umidecimento;

DTH = Variação do conteúdo de água na frente de umidecimento. 


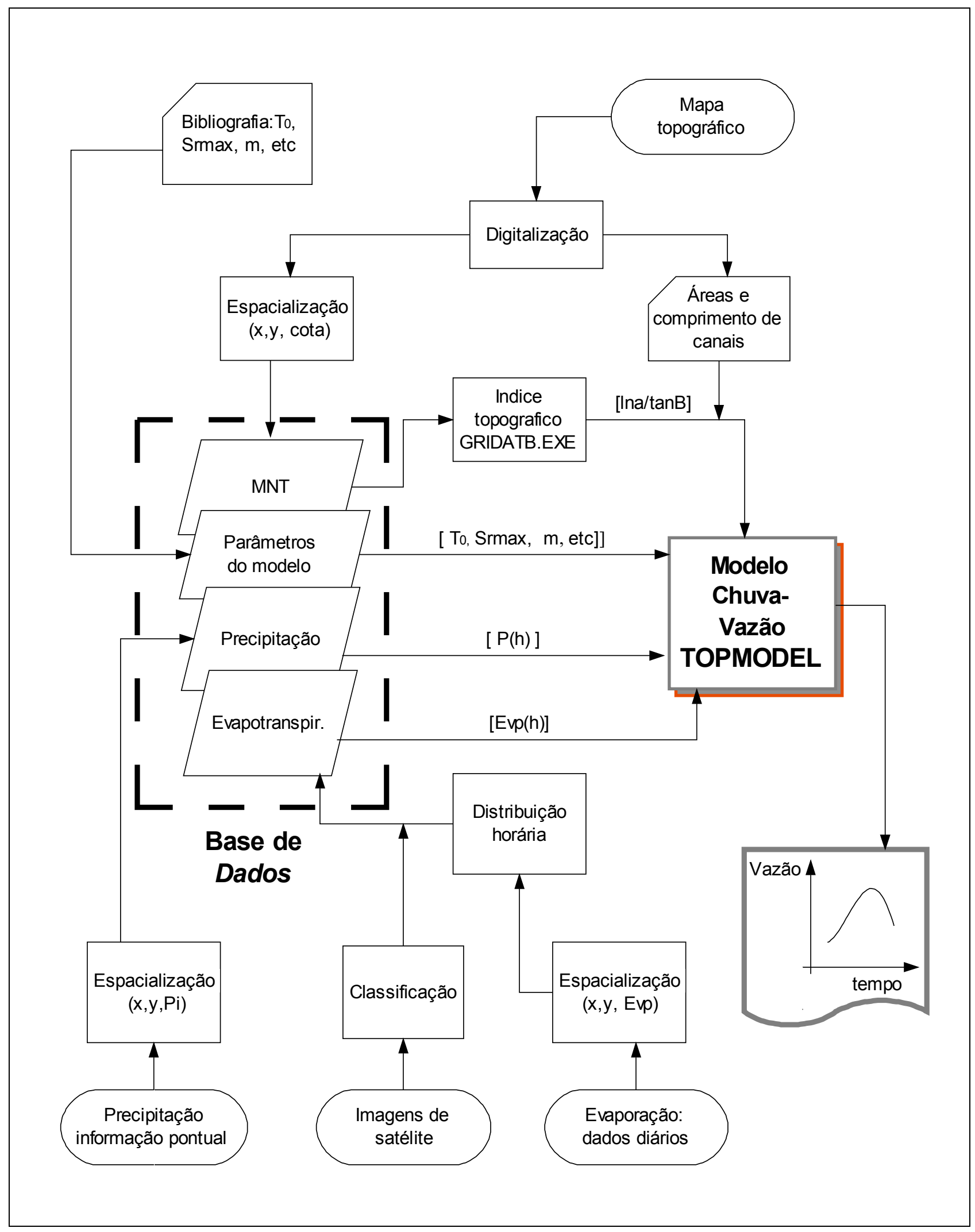

Figura 4. Estrutura de integração de atividades para utilização do modelo TOPMODEL (fonte: Varella, 1998). 
Os parâmetros $\mathrm{K}_{0}$, condutividade hidráulica de saturação da superfície do solo, HF, valor de sucção na frente de umidecimento e DTH, variação do conteúdo de Os parâmetros $\mathrm{K}_{0}$, condutividade hidráulica de saturação da superfície do solo, HF, valor de sucção na frente de umidecimento e DTH, variação do conteúdo de água na frente de umidecimento são utilizados no bloco do programa onde é feito o cálculo de escoamento superficial quando há excedência de infiltração. Quando se têm valores muito altos de condutividade hidráulica de saturação da superfície do solo, provavelmente não se verificará a formação de escoamento superficial por este mecanismo, uma vez que os valores de intensidade de precipitação são muito menores que estes valores atribuídos a $\mathrm{K}_{0}$. Assim, nestas condições, estes parâmetros não são utilizados nos cálculos feitos pelo modelo, não apresentando, praticamente, nenhuma influência nos resultados obtidos. Os valores utilizados para $\mathrm{K}_{0}=1,0 \mathrm{~m} \cdot \mathrm{h}^{-1}$, para $H F=0,002 \mathrm{~m}$ e para $\mathrm{DTH}=0,1$ foram os mesmos utilizados por Beven et al. (1994).

O parâmetro $S_{r 0}$, que é definido como sendo o déficit inicial na zona das raízes especifica o estado inicial de umidade do solo, e é assumido no modelo como um único valor, válido para toda a bacia. É usado apenas uma vez, no início dos cálculos, sendo atribuído à variável que recebe o valor do déficit de armazenamento na zona das raízes calculado a cada intervalo de tempo. Sua influência nos resultados do modelo é muito pequena. Foi empregado o mesmo valor utilizado por Beven et al. (1994), ou seja 0,002 m.

O tempo de permanência na zona não saturada por unidade de déficit, $t_{d}$, traduz a capacidade de retenção de água, sendo empregado na equação de cálculo do fluxo vertical da zona não saturada. O valor empregado neste estudo foi o mesmo utilizado por Beven et al. (1994) e por Mine \& Clarke (1996), 50 h.m ${ }^{-1}$.

Em todas as aplicações do TOPMODEL apresentadas nos trabalhos anteriormente mencionados, quatro parâmetros críticos invariavelmente são os responsáveis pela resposta do modelo. São eles: $m$, parâmetro de decréscimo exponencial da transmissividade; $\mathrm{T}_{0}$, transmissividade do solo saturado à superfície; $\mathrm{S}_{\mathrm{r} \text { max }} \mathrm{O}$ armazenamento máximo de água na zona das raízes e, para bacias grandes, CHV a velocidade de propagação no canal principal.

O valor parâmetro do modelo $\mathrm{m}$, ou de decréscimo exponencial da transmissividade, está diretamente relacionado com a forma do ramo de recessão do hidrograma observado na seção de saída da bacia. Expressa também a profundidade real do perfil de umidade do solo da bacia, atuando interativamente com $\mathrm{T}_{0}$. Estes dois parâmetros se relacionam conforme se mostra na Equação (2).

$\mathrm{Na}$ Tabela 1 são mostrados os valores iniciais assumidos para os parâmetros, e os valores de partida, utilizados na calibração do modelo.

\section{Tabela 1. Parâmetros usados na calibração do modelo.}

\begin{tabular}{lcc}
\hline Parâmetro & Valor & Unidade \\
\hline $\mathrm{m}$ & 0,100 & $\mathrm{~m}$ \\
$\mathrm{~S}_{\mathrm{r} 0}$ & 5,000 & $\mathrm{~m}^{2} \cdot \mathrm{h}^{-1}$ \\
$\mathrm{td}$ & 50,000 & $\mathrm{~h} \cdot \mathrm{m}^{-1}$ \\
$\mathrm{CHV}$ & 1,000 & $\mathrm{~km} \cdot \mathrm{h}^{-1}$ \\
$\mathrm{RV}$ & 1,000 & $\mathrm{~km} \cdot \mathrm{h}^{-1}$ \\
$\mathrm{~S}_{\mathrm{r} \text { max }}$ & 0,050 & $\mathrm{~m}$ \\
$\mathrm{~S}_{\mathrm{r} 0}$ & 0,002 & $\mathrm{~m}$ \\
$\mathrm{~K}_{0}$ & 1,000 & $\mathrm{~m} \cdot \mathrm{h}^{-1}$ \\
$\mathrm{HF}$ & 0,020 & $\mathrm{~m}$ \\
DTH & 0,100 & Adimens. \\
\hline
\end{tabular}

\section{PRECIPITAÇÃO}

Embora o TOPMODEL possa ser classificado como modelo semi-distribuído, processa, a cada intervalo de tempo, um único valor de precipitação para toda a bacia. As informações sobre precipitação disponíveis eram valores horários para duas estações e médias mensais para outras 3 estações localizadas no entorno da bacia. Todos os valores históricos mensais foram obtidos no banco de dados do Microsistema de Dados Hidrometeorológicos - MSDHD do Departamento Nacional de Águas e Energia Elétrica - DNAAE.

Os valores históricos de precipitação, para as estações de Taguatinga, Braslândia, Descoberto e Jatobazinho foram calculados fazendo a média aritmética dos valores médios de cada mês, de 1980 até 1997 e, para o posto da Fazenda Sta. Elisa a média histórica foi calculada a partir de 1989.

A análise destes dados mostrou uma distribuição espacial não uniforme para esta variável. Para se determinar esta distribuição da precipitação na bacia, foi feita a distribuição espacial pelo método de Kriging, dos valores médios mensais utilizando dados destas cinco estações. Neste procedimento, utilizou-se modelo linear para o semivariograma, não havendo direção preferencial na distribuição espacial dos dados. Considerou-se também, que o hietograma da estação para a qual se dispunha de registro seja representativo da distribuição temporal em toda a bacia. A Figura 5 mostra o resultado da distribuição espacial para 


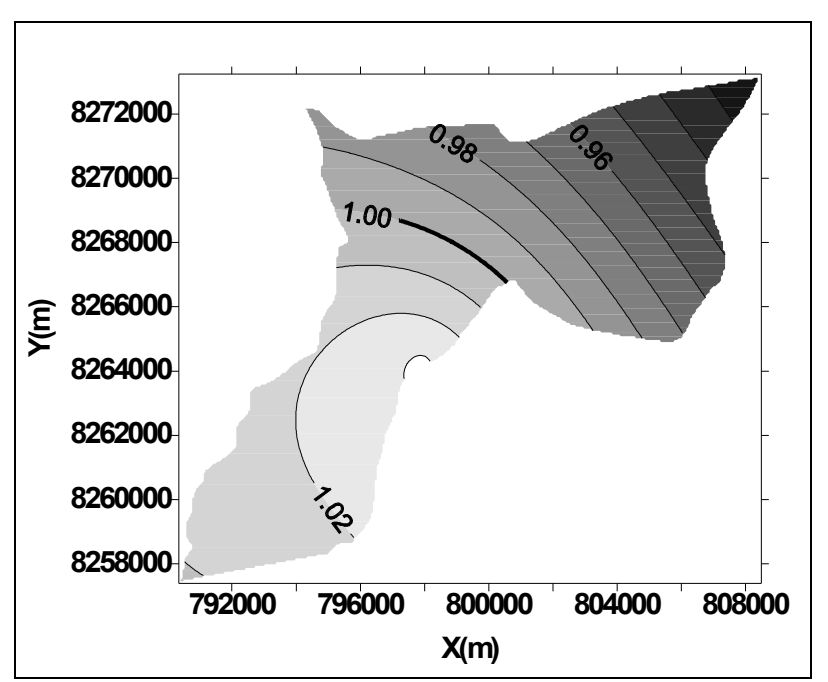

Figura 5. Distribuição espacial da precipitação - referência estação Descoberto fevereiro de 1988.

fevereiro de 1988, tendo como base os registros horários obtidos na estação Descoberto (DNAAE 01548008).

Após a distribuição espacial, foi gerado um mapa contendo as isoietas adimensionais, resultantes da divisão do valor da precipitação num dado posto pela precipitação medida no posto com registro horário. Este processo permite estimar o valor da precipitação para qualquer local da bacia, conhecendo-se a intensidade de precipitação horária numa dessas duas estações, fazendo a leitura do valor da isolinha que passa nesse local no gráfico relativo ao mês e ao ano da medida, multiplicando-o pelo valor na estação com registro.

Observa-se, nesta figura, que é possível identificar áreas que apresentam precipitação homogênea, podendo-se também compor um fator ponderado, que resulta do produto de uma porcentagem da área total pelo seu respectivo valor de precipitação representado na figura pela região entre isolinhas consecutivas.

Este procedimento foi repetido para todos os meses, para os quais se tinha dados, obtendose desta forma todos os fatores desejados. A Tabela 2 a seguir, mostra os valores dos fatores ponderados para toda a bacia.

Finalmente, estes fatores foram usados na correção dos valores horários de precipitação das estações de Descoberto e Braslândia.

\section{EVAPOTRANSPIRAÇÃO}

A evapotranspiração real, que é o valor utilizado pelo modelo no balanço de água, é calcula-
Tabela 2. Fatores ponderados para cálculo da precipitação média na bacia do rio Descoberto.

\begin{tabular}{cccc}
\hline Mês & Ano & $\begin{array}{c}\text { Estação de } \\
\text { referência }\end{array}$ & $\begin{array}{c}\text { Fator de cor- } \\
\text { reção }\end{array}$ \\
\hline Fever. & 1988 & Descoberto & 0,9869 \\
Março & 1988 & Descoberto & 1,1280 \\
Março & 1995 & Braslândia & 0,9728 \\
Abril & 1995 & Braslândia & 0,9810 \\
\hline
\end{tabular}

da em cada intervalo de tempo, através da Equação (3), sendo função do máximo déficit possível na zona das raízes, $S_{r \max }$, do déficit na zona das raízes no instante de tempo que está sendo calculado, $S_{r z}$ e da evapotranspiração potencial, $E_{p}$. $O$ valor do déficit na zona das raízes é um valor atualizado pelo modelo a cada intervalo de tempo; o valor do máximo déficit possível é um valor constante para toda a bacia sendo passado ao modelo na forma de parâmetro e, similarmente à precipitação, o modelo requer um único valor de evapotranspiração potencial, válido para toda bacia, a cada intervalo de tempo.

Embora na região de abrangência da bacia do rio Descoberto exista uma estação climatológica, não se dispunha de dados de evapotranspiração para as épocas estudadas e por esta razão foram usados dados de evaporação medidos na estação da UnB.

Os valores de evapotranspiração potencial, foram obtidos multiplicando o valor da evaporação por um fator que depende do tipo de cobertura do solo, representando este fator, uma porcentagem da evaporação que ocorre numa superfície livre de água medida em tanque classe $\mathrm{A}$.

A determinação do tipo de cobertura foi feita, a partir da classificação de imagens referentes às bandas 3,4 e 5 do satélite Landsat TM, para 1988 e 1995. Antes de fazer a classificação, as imagens foram interpretadas visualmente para se identificar as classes de cobertura de interesse a este trabalho, presentes nas cenas. Foram consideradas cinco classes: campo limpo, ocupação urbana, solo exposto, vegetação e corpos de água.

Os valores dos fatores de correção da evaporação medida em tanque classe A para cada um dos tipos de cobertura, foram obtidos na literatura especializada.

Esses dados de evaporação diária foram então convertidos para evapotranspiração potencial, considerando neste cálculo a influência dos diversos tipos de cobertura do solo da bacia, obtidos a partir da classificação de imagens do satélite Landsat TM. Finalmente, os valores diários de eva- 
potranspiração, já corrigidos pelos fatores que consideraram o tipo de cobertura do solo, foram multiplicados pelos percentuais horários mostrados na Figura 6, obtendo-se assim o valores da evapotranspiração potencial que foram utilizadas pelo modelo.

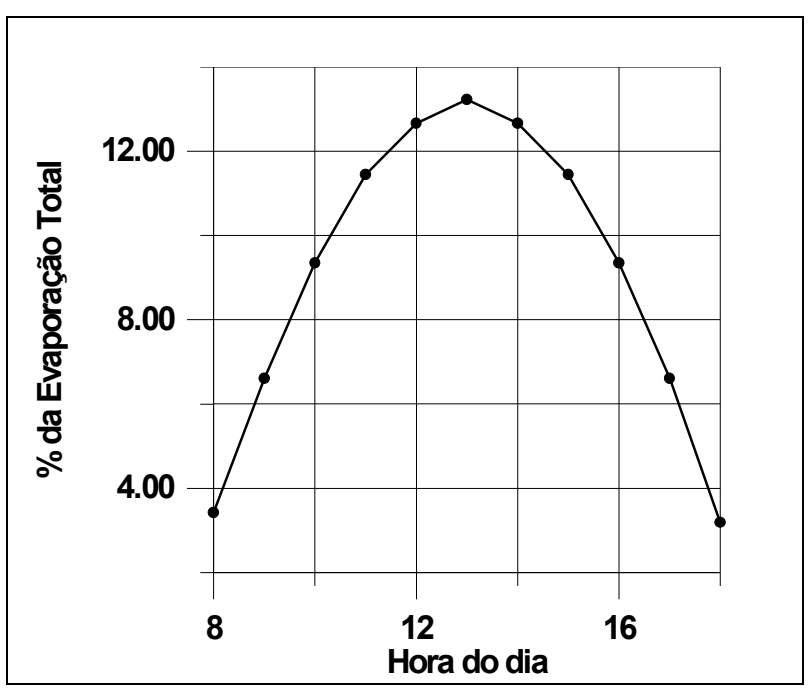

Figura 6. Distribuição, ao longo do dia, da evapotranspiração potencial.

\section{ÍNDICE TOPOGRÁFICO}

Além da influência dos principais parâmetros, os resultados produzidos pelo TOPMODEL dependem também dos valores da declividade do terreno que são calculados na forma de índice topográfico de Kirkby e Beven, In(a/tan $\beta)$, obtido a partir do modelo numérico do terreno.

Neste trabalho foram gerados sete modelos numéricos do terreno, dos quais quatro, resoluções espaciais de 30, 90, 150 e 210 m (Figura 7) foram utilizados nos cálculos das distribuições deste índice em função da porcentagem de área acumulada, mostradas na Figura 8. Como se pode observar nesta figura, à medida que se aumenta a resolução espacial do MNT, através da diminuição do lado da grade, a distribuição dos valores de índice topográfico em função da porcentagem da área total é alterada, apresentando valores máximos, mínimos e médias progressivamente menores. Cada uma das distribuições de índice topográfico, irá produzir como resultado da calibração do modelo, um determinado conjunto de valores para os principais parâmetros, conforme será mostrado.

Pode-se representar graficamente na área da bacia, as isolinhas de índices topográficos, que foram calculados com auxílio do programa
GRIDATB, para as diversas resoluções espaciais do MNT. À medida que se aumenta o lado do elemento unitário da grade do MNT, e portanto, da área de drenagem usada no cálculo do índice topográfico, vai se perdendo o detalhamento da distribuição espacial deste índice.

Outra conseqüência do uso de áreas de maior tamanho, no cálculo deste índice, é o deslocamento da distribuição no sentido dos maiores valores de índice topográfico, o que é observado, também, com os valores médios da distribuição conforme pode-se observar na Figura 8.

Nas margens dos canais de drenagem, observa-se uma grande variação do índice topográfico, o que é indicado pela grande concentração de isolinhas que apresentam simetria em relação aos canais. Nestes, o índice topográfico calculado assume os maiores valores da escala, pois as declividades devem ser as menores.

Na Figura 9 são apresentados dois gráficos mostrando as isolinhas de índices topográficos calculados a partir de resoluções espaciais do modelo numérico do terreno de $90 \mathrm{~m}$ e $210 \mathrm{~m}$.

\section{CALIBRAÇÃo}

Na calibração do modelo foi utilizada uma coleção de dados de precipitação obtidos na estação Descoberto e de vazões medidas na estação localizada na saída da bacia.

Na Figura 10 são mostrados os valores de precipitação e vazão para este intervalo de tempo e especificados os cinco eventos chuvosos empregados na calibração do modelo.

Assim, para se determinar os valores dos parâmetros do modelo, foram utilizados estes cinco eventos chuvosos e, para cada um deles, foram consideradas quatro alternativas de distribuições de índice topográfico, das sete disponíveis, totalizando vinte conjuntos de dados de partida.

Com a finalidade de auxiliar na estimativa dos valores dos parâmetros para as diversas situações testadas, foi calculado um fator global chamado de FG, que é simplesmente um valor médio entre o volume total de água (somatório do produto da vazão pelo tempo) e a vazão máxima, calculados em relação aos valores observados:

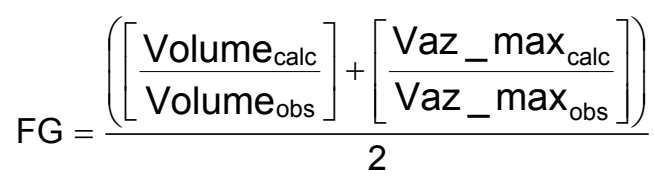

onde FG é o fator global; Volume calc $_{\text {é o volume }}$ total calculado pelo modelo; Volume obs, $_{0}$ volume 


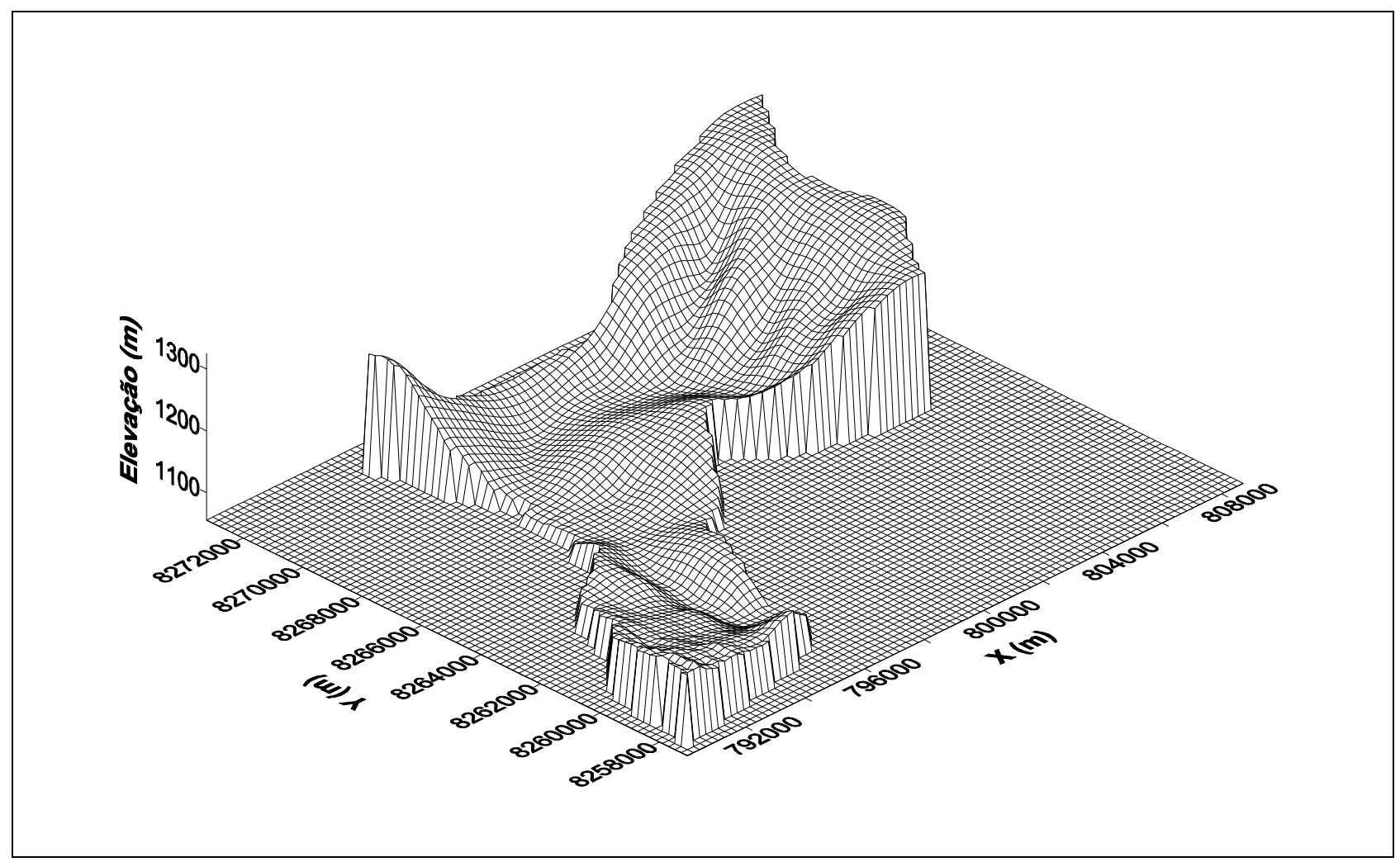

Figura 7. Modelo numérico do terreno - grade 210 m - bacia do rio Descoberto, Brasília - DF.

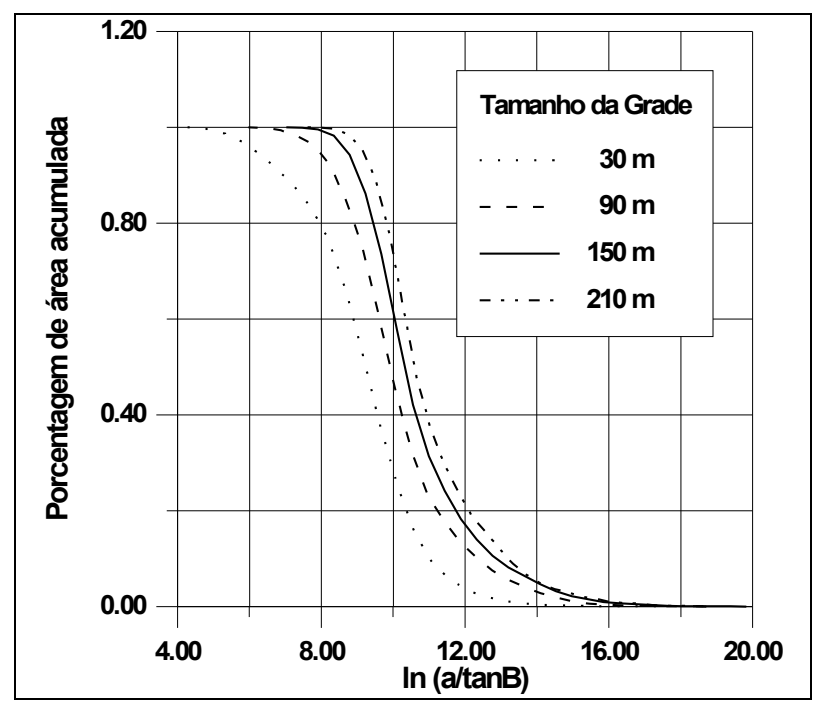

Figura 8. Distribuição do índice topográfico bacia do rio Descoberto, Brasília - DF.

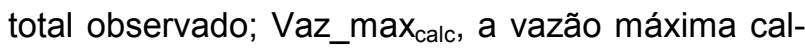
culada pelo modelo ē Vaz_max ${ }_{\text {obs }}$ a vazão máxima observada.

Este fator global não leva em consideração o desvio que pode ocorrer entre o hidrograma calculado e o observado, o que é determinado pelo fator E, o coeficiente de Nash e Sutcliffe, que for- nece uma indicação da qualidade do ajuste do hidrograma calculado ao observado.

O modelo calcula $E$ para cada conjunto de dados processados, através da seguinte equação, discutida por Beven et al. (1994):

$$
E=1-\frac{\sigma_{e}}{\sigma_{0}}
$$

onde $\sigma_{e}$ é a variância dos resíduos e $\sigma_{o}$ a variância dos valores de vazões observadas.

$O$ valor de $E$ indica a qualidade do ajuste do modelo aos dados observados sendo que os melhores ajustes são aqueles próximos de 1. Mine \& Clarke (1996), adotaram como critério para avaliar os resultados que, valores de $\mathrm{E}$ maiores que 0,7 representam ajustes de alta eficiência.

Assim, usando o conjunto de valores dos parâmetros mostrados na Tabela 1, para um dado evento e uma dada distribuição de índice topográfico ou tamanho da grade do MNT, o modelo foi executado mantendo-se fixo o valor de $\ln \mathrm{T}_{0}$ e variando o valor do parâmetro $m$ de 0,1 a 1,9 vezes o valor inicial, isto é, de 0,01 até 0,19 , com incrementos de 0,05 , resultando um total de 37 valores de $\mathrm{m}$ para cada valor de $\ln \mathrm{T}_{0}$ testado. 

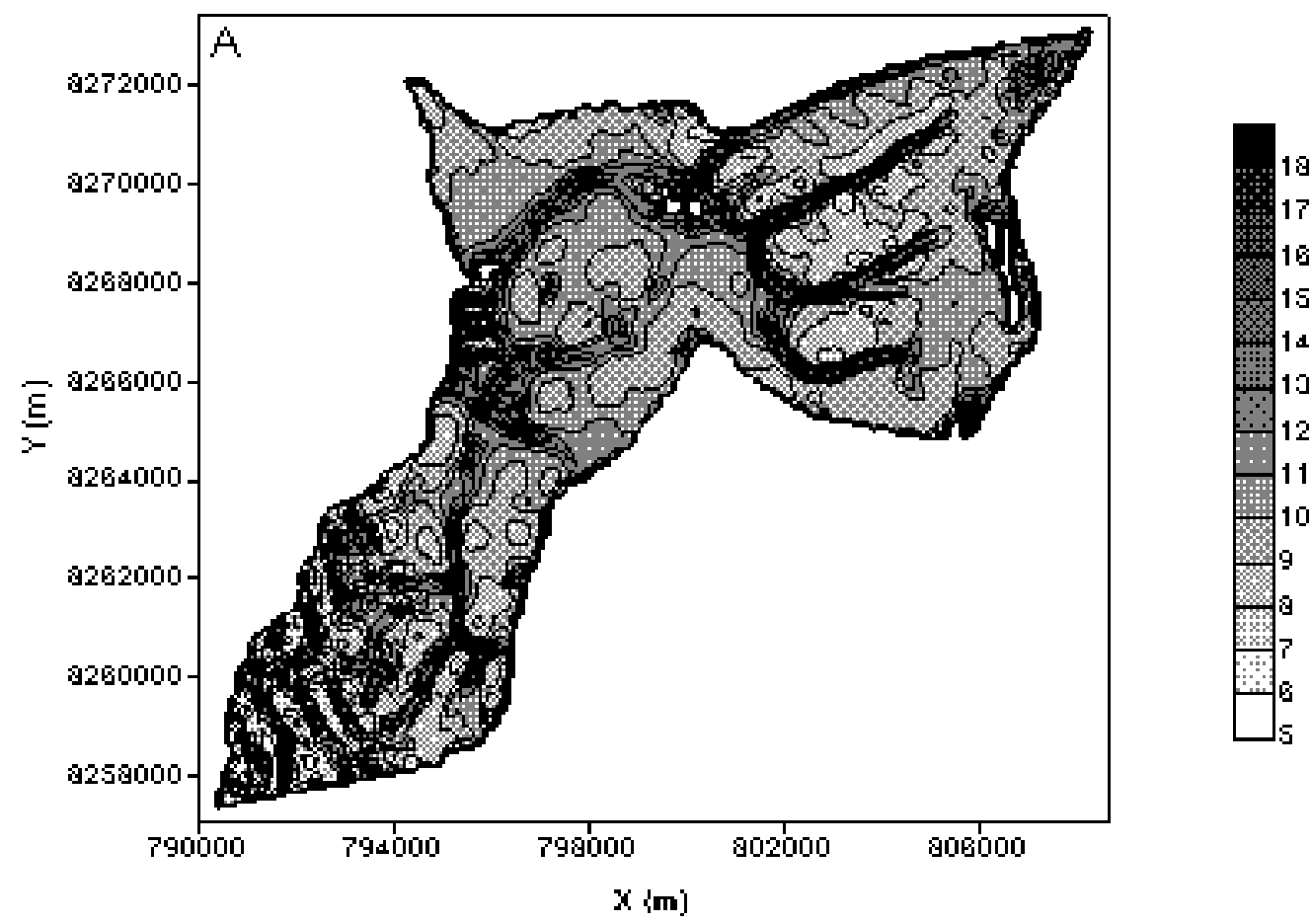

A. Resolução espacial do MNT de 90m
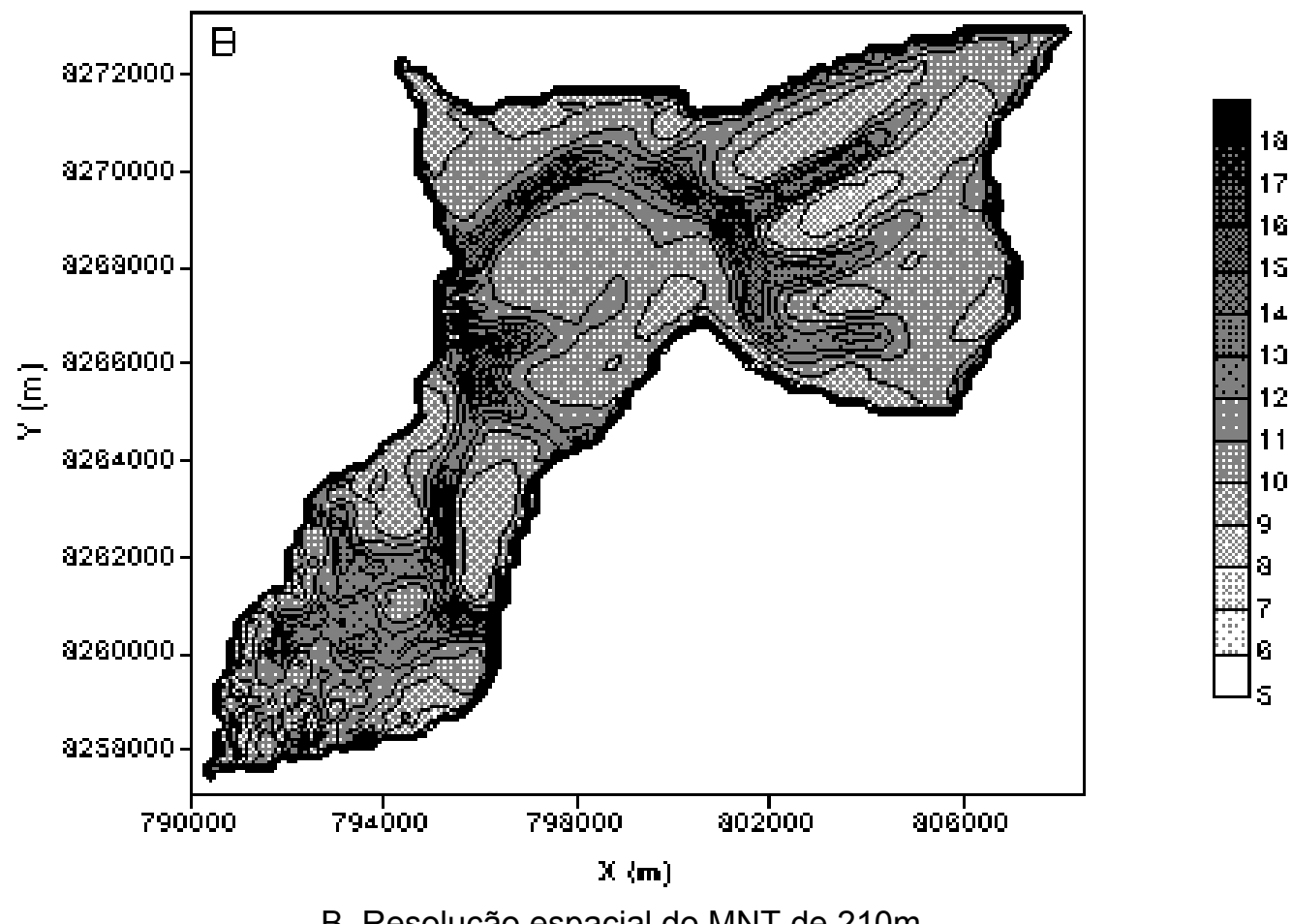

Figura 9. Distribuição dos valores de índice topográfico. 


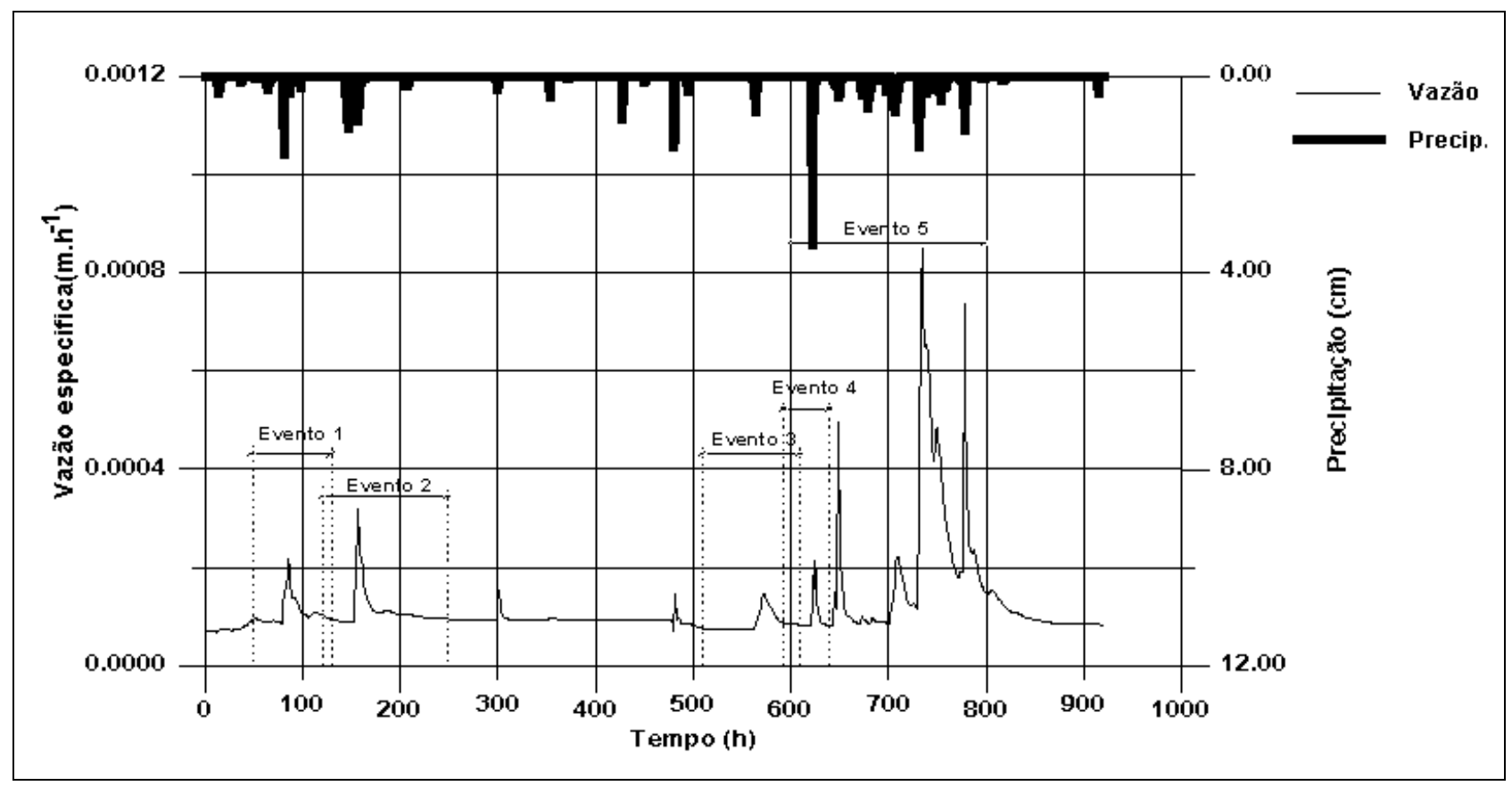

Figura 10. Precipitação e vazão, bacia do rio Descoberto - Início: 11/02/1998 às 8:00 horas.

A quantidade de valores de transmissividade testada em cada caso, variou de acordo com os resultados obtidos em cada um deles. O modelo foi também aplicado para se determinar o valor de $\mathrm{S}_{\mathrm{r} \max }$. A Figura 11 mostra os resultados obtidos para os 5 eventos considerando resolução espacial do MNT de $90 \mathrm{~m}$.

$\mathrm{O}$ único evento que apresentou um comportamento diferente dos demais foi o 3 , o que dificultou a estimativa do valor de $\mathrm{T}_{0}$ devido à forma das curvas obtidas.

Para uma faixa relativamente ampla de variação nos valores de $S_{r \max }$, praticamente não são observadas alterações nos resultados obtidos. Para valores próximos ao do déficit inicial na zona das raízes, que no caso foi de $0,002 \mathrm{~m}$, o modelo apresenta pequenas alterações nos valores relativos de vazões máximas e volumes. Portanto, este parâmetro deverá apresentar pouca interferência nos resultados gerados pelo TOPMODEL.

Em cada um dos vinte gráficos obtidos neste procedimento foram lidos os valores de $m$ e $T_{0}$ para as curvas que apresentaram tendência assintótica para FG igual a 1. A Tabela 3 apresenta os resultados das estimativas dos valores do parâmetro $\mathrm{m}$ para cada evento e grade do MNT.

Esta tabela mostra que, em uma única combinação de evento chuvoso/grade do MNT, das vinte estudadas, esse parâmetro apresentou o mesmo valor inicial, $0,1 \mathrm{~m}$, sendo que em todas as outras, este valor foi superado.
Tabela 3. Estimativa do valor de $\mathbf{m}$.

\begin{tabular}{ccccc}
\hline & \multicolumn{4}{c}{ Parâmetro $m(m)$} \\
Evento & \multicolumn{3}{c}{ Resolução } & MNT $(\mathrm{m})$ \\
& 30 & 90 & 150 & 210 \\
\hline 1 & 0,10 & 0,12 & 0,12 & 0,12 \\
2 & 0,14 & 0,18 & 0,16 & 0,16 \\
3 & 0,14 & 0,14 & 0,16 & 0,16 \\
4 & 0,16 & 0,12 & 0,12 & 0,14 \\
5 & 0,17 & 0,18 & 0,18 & 0,18 \\
\hline
\end{tabular}

O método empregado mostrou que, para as vinte alternativas estudadas, o valor do parâmetro $\mathrm{m}$ apresentou um valor médio de $0,15 \mathrm{~m}$. As maiores variações nos valores médios deste parâmetro foram verificadas entre os eventos chuvosos estudados, de 0,12 a 0,17 m. As variações observadas com relação à resolução espacial da grade do MNT foram menores, 0,14 a 0,15 m.

Portanto, assumir o valor médio significa que para os eventos que na calibração admitiram valores menores que este, haverá um deslocamento do hidrograma no sentido de menores de vazões e, para os eventos que na calibração apresentaram estimativas do parâmetro $\mathrm{m}$ maiores que o média, o uso deste último valor implica no aumento dos valores das vazões calculadas.

Os valores obtidos na calibração para o parâmetro $T_{0}$, para cada um dos eventos estudados, em função do lado da grade do MNT são apresen- 


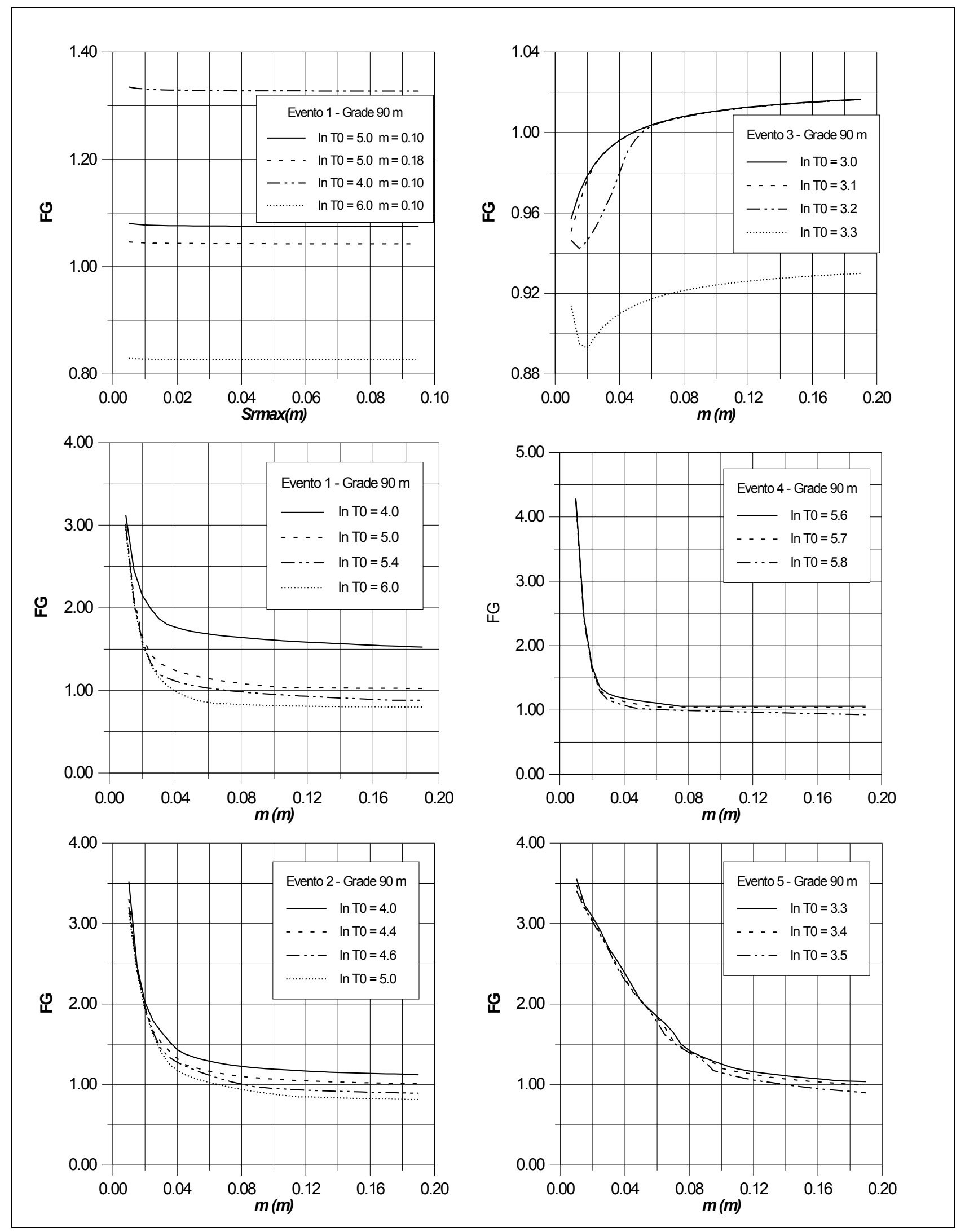

Figura 11. Determinação dos valores dos parâmetros do modelo. 
tados Figura 12. A variação no parâmetro $T_{0}$ foi pronunciada tanto para os diferentes eventos como para o tamanho da grade, sendo observada neste caso uma tendência a variações cada vez menores à medida que a resolução espacial do MNT diminui, isto é, lado da grade crescente, como pode ser observado nesta Figura 12.

A partir dos resultados mostrados na Tabela 3, estimativas do parâmetro $\mathrm{m}$ e na Figura 12 pode-se observar que os valores dos dois principais parâmetros do modelo, $\mathrm{m}$ e $\mathrm{T}_{0}$ apresentaram variações em relação aos diferentes eventos chuvosos considerados. Em particular a transmissividade $T_{0}$, mostrou grande variação em função da resolução espacial da grade do MNT.

$\mathrm{Na}$ estrutura de cálculo do modelo o parâmetro $\mathrm{CHV}$ se refere à velocidade de viagem no canal principal e RV a velocidades nos canais das sub-bacias. Nesta aplicação do modelo a área total da bacia foi dividida em três sub-áreas, conforme pode ser visto na Figura 13.

Nesta divisão da área da bacia, CHV foi atribuída ao escoamento em canal na sub-área 1 que é a mais próxima da saída da bacia enquanto o valor do segundo parâmetro RV foi aplicado às sub-áreas 2 e 3.

Estes dois parâmetros são utilizados no cálculo do tempo gasto pela água para ir destas sub-áreas até a seção de saída da bacia, influenciando no valor do tempo ao pico calculado pelo modelo, independentemente do volume transportado e também da resolução espacial utilizada no MNT.

Em três dos cinco eventos estudados, o parâmetro de velocidade $\mathrm{RV}$, foi estimado em $1,80 \mathrm{~km} \cdot \mathrm{h}^{-1}$ e nos outros dois, $1,50 \mathrm{~km} \cdot \mathrm{h}^{-1} \mathrm{e}$ $0,90 \mathrm{~km} \cdot \mathrm{h}^{-1}$. Já o parâmetro de velocidade $\mathrm{CHV}$ apresentou maior variação, alcançando valor máximo de $2,50 \mathrm{~km} \cdot \mathrm{h}^{-1}$ para o evento 5 , que foi aquele onde se verificou os maiores valores de vazão de pico.

Os resultados apresentados indicam que o modelo é bastante sensível ao parâmetro $\mathrm{T}_{0}$. Observa-se também, que os valores obtidos na calibração do modelo para este parâmetro, dependem diretamente da resolução espacial do modelo numérico do terreno, o que foi verificado para todos os eventos utilizados na calibração.

O parâmetro $\mathrm{m}$, que está relacionado com a forma do ramo recessivo do hidrograma, apresentou variação pequena com relação à resolução espacial do MNT, nos cinco eventos estudados. A variação dos valores médios deste parâmetro entre eventos foi ligeiramente superior àquela.

O conjunto de valores para os parâmetros do modelo que apresentam os melhores resultados

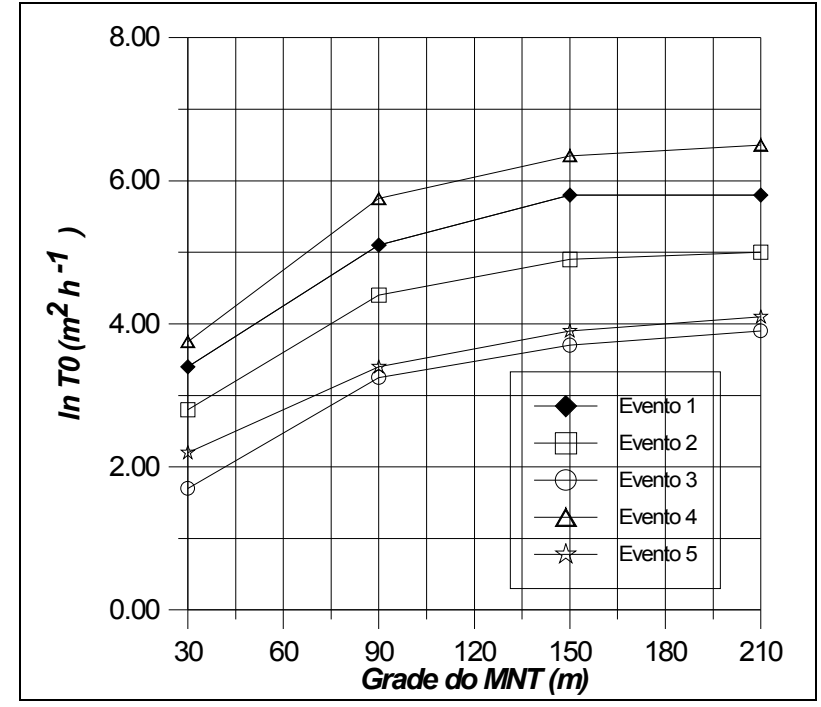

Figura 12. Estimativa de To para 5 eventos.

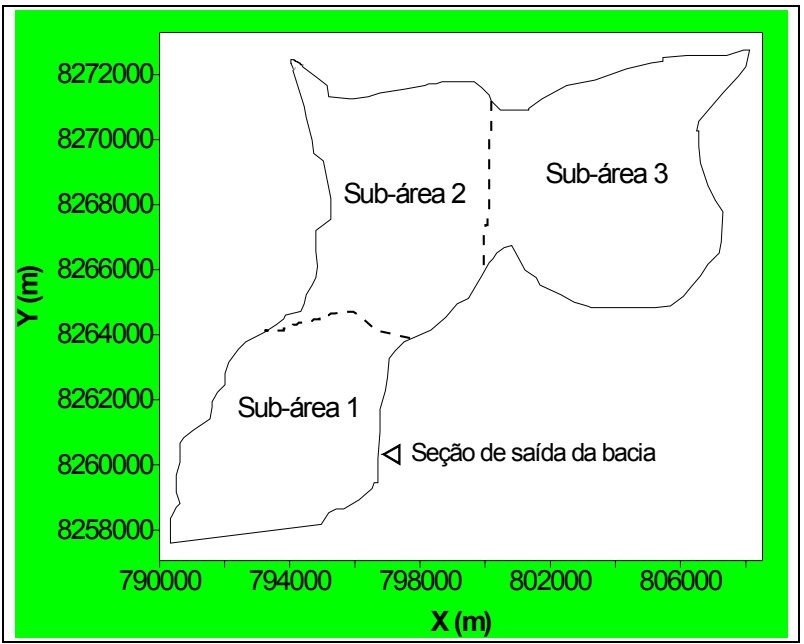

Figura 13. Divisão da bacia em sub-áreas.

para a série completa de dados, $920 \mathrm{~h}$ foram os obtidos na calibração com o evento 5 , conforme apresenta-se na Figura 14, para resolução espacial do modelo numérico do terreno de $90 \mathrm{~m}$.

Da mesma forma, os parâmetros de velocidade que apresentaram melhor ajuste para os tempos ao pico foram obtidos neste mesmo evento, $\mathrm{RV}=1,80 \mathrm{~km} \cdot \mathrm{h}^{-1}$ e $\mathrm{CHV}=2,50 \mathrm{~km} \cdot \mathrm{h}^{-1}$.

\section{ESTUDO DE SENSIBILIDADE}

Para se estudar a influência dos principais parâmetros, $T_{0}, m$ e $S_{r \max }$ foram utilizados os arquivos de dados sequenciais de precipitação, evapotranspiração e vazão. 


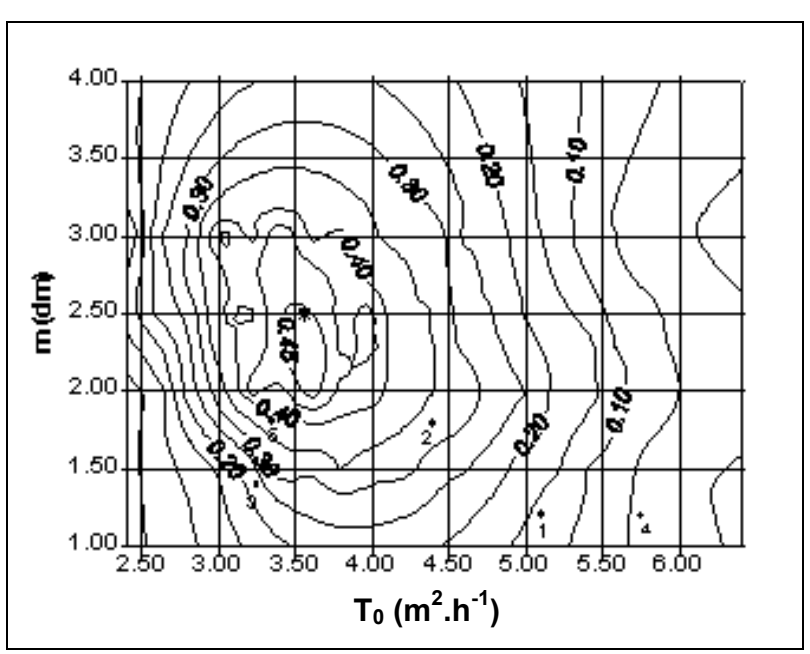

Figura 14. Valores de E - Nash-Sutcliffe em função de m e To. Grade $90 \mathrm{~m}$.

Com o objetivo de estudar um determinado parâmetro, foram mantidos constantes todos os outros e, o modelo foi executado para cada valor atribuído ao parâmetro.

Foram calculadas as relações entre valores produzidos pelo modelo e os observados (valores relativos) para o volume total do escoamento superficial, vazão máxima e tempo ao pico.

Os resultados dos estudos de sensibilidade apresentados nas Figuras 15 a 17 para os parâmetros $\mathrm{m}, \mathrm{T}_{0}$ e $\mathrm{S}_{\mathrm{r} \text { max }}$, estão de acordo as informações levantadas na bibliografia, destacando a influência dos dois primeiros nos resultados, o que pode ser constatado pela observação da variação dos valores do coeficiente $E$ e das vazões e volumes relativos, calculados em relação aos observados.

O valor original de $S_{r \max }$ assumido foi de $0,05 \mathrm{~m}$. Verifica-se que, para uma faixa relativamente ampla de variação nos valores deste parâmetro, praticamente não são observadas alterações nos resultados obtidos. Para valores próximos ao do déficit inicial na zona das raízes, que no caso foi de $0,002 \mathrm{~m}$, o modelo apresentou alterações nos valores relativos de vazões máximas, volumes e no valor de $\mathrm{E}$.

Portanto, a influência de $S_{r \max }$ deve ser considerada em condições, onde a diferença entre seu valor e a referência do estado inicial de umidade do solo, $\mathrm{S}_{\mathrm{r} 0}$ é pequena.

Os parâmetros de velocidade estão diretamente relacionados ao valor de tempo, ao pico calculado pelo modelo. Para se mostrar a sensibilidade do modelo a estes parâmetros analisou-se o evento 1 que apresentou pico de vazão ocorrendo 34 horas após seu início. Os resultados são mostrados na Figura 18.

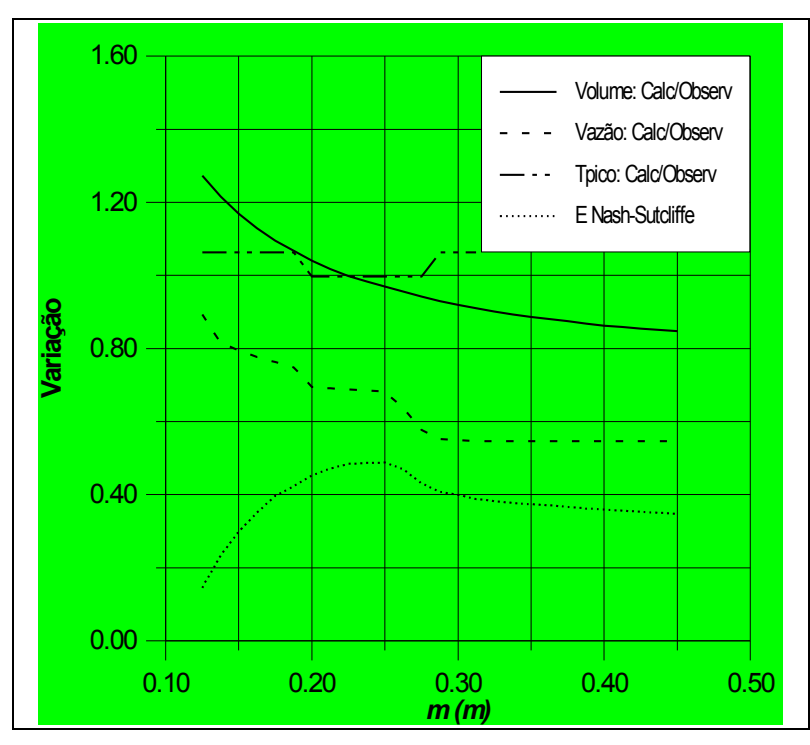

Figura 15. Sensibilidade do modelo ao parâmetro $\mathbf{m}$.

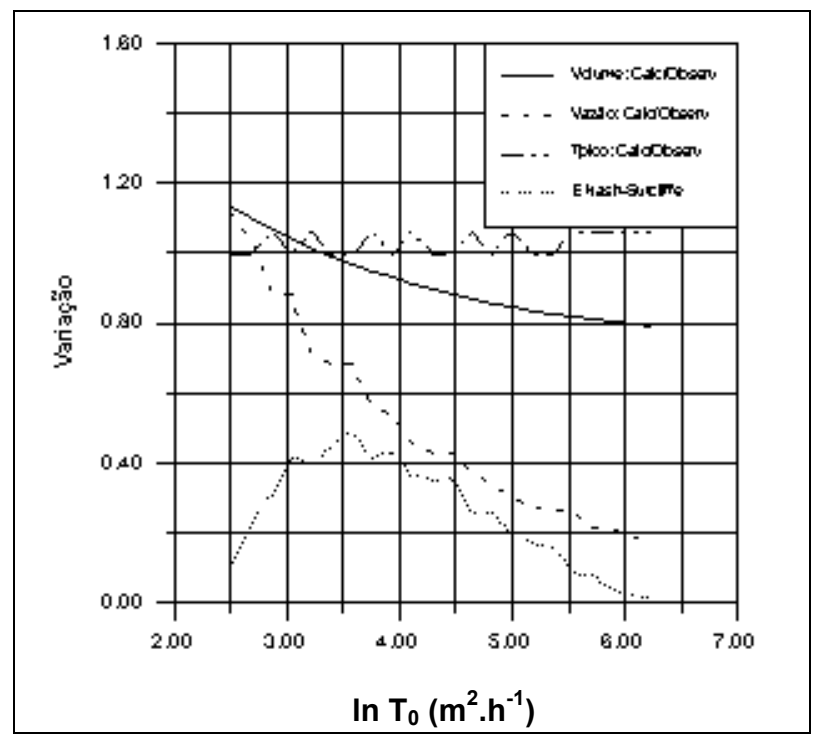

Figura 16. Sensibilidade do modelo ao parâmetro To.

Embora seja possível obter valores do coeficiente $E$ de Nash e Sutcliffe próximos a 0,60 para $\mathrm{CHV}=2,50 \mathrm{~km} \cdot \mathrm{h}^{-1}$ conforme pode ser observado na Figura 18, o valor deste parâmetro que resulta em iguais valores de tempo ao pico, calculado pelo modelo e observado, é igual a $1,25 \mathrm{~km} \cdot \mathrm{h}^{-1}$, enquanto que RV, que resultou em maior valor do coeficiente Nash e Sutcliffe $(E=0,520)$ foi $1,8 \mathrm{~km} \cdot \mathrm{h}^{-1}$.

A escolha individual do melhor valor de cada parâmetro como sendo aquele que apresenta o maior valor do índice $\mathrm{E}$, não garante um ajuste do modelo de boa qualidade, porque a análise de 


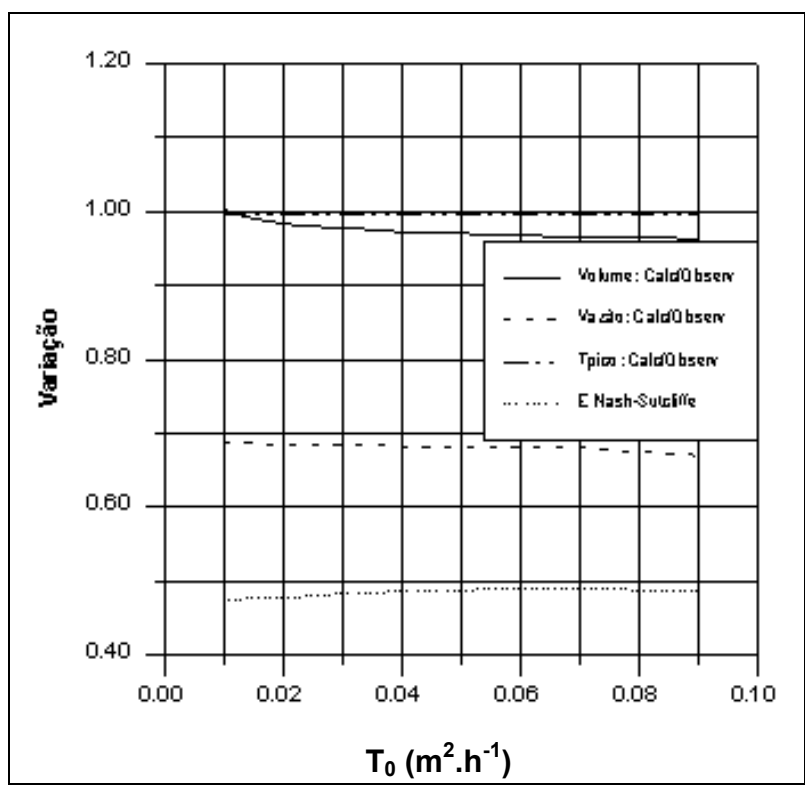

Figura 17. Sensibilidade do modelo ao parâmetro $S_{r}$ max.

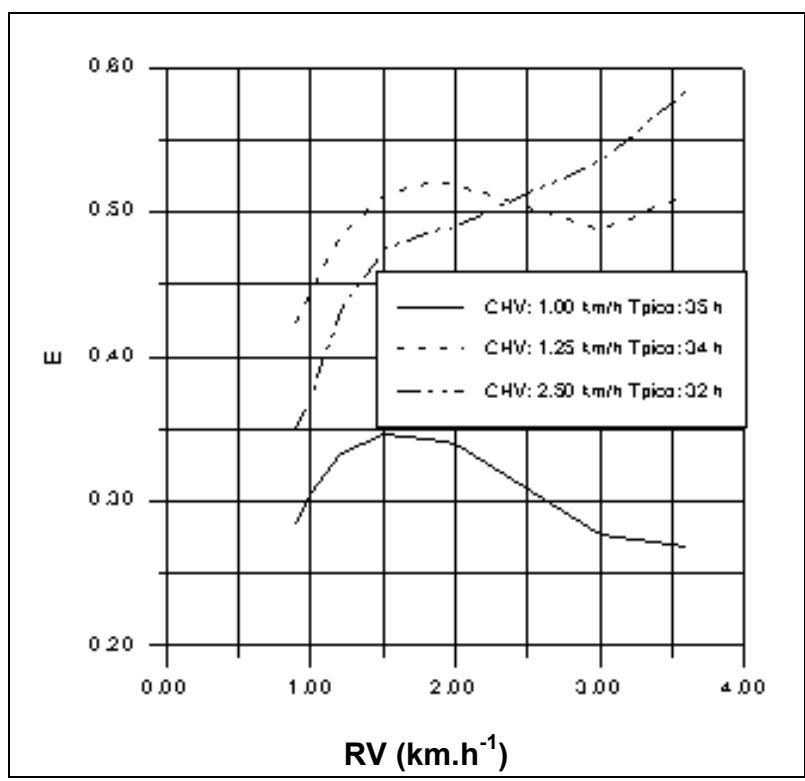

Figura 18. Sensibilidade do modelo ao parâmetro CHV e RV.

sensibilidade é feita considerando o efeito isolado de cada parâmetro, mas na prática existe um efeito combinado de todos eles.

\section{APLICAÇÃO DO MODELO}

Na Figura 19 pode-se observar o resultado da aplicação do modelo à serie completa de dados, 920 horas. As quatro resoluções espaciais estuda- das produzem o mesmo resultado para distintos conjuntos de parâmetros, estimados em função da resolução espacial. Optou-se pelo emprego do conjunto de parâmetros obtidos na calibração com o evento 5 , pois foi neste evento que se obteve o valor do parâmetro $\mathrm{m}$ que mostrou o melhor ajuste ao ramo recessivo do hidrograma, especialmente para os maiores picos de vazão. Da mesma forma, os parâmetros de velocidade que apresentaram melhor ajuste para os tempos ao pico foram obtidos neste mesmo evento.

Nas simulações realizadas, obteve-se ajustes razoáveis para volume, para o valor da vazão máxima de pico e tempo de pico, no entanto os valores de $\mathrm{E}$ resultantes foram pequenos, menores que $\mathrm{O}$ valor assumido como referência, 0,7 , indicando que o modelo não conseguiu reproduzir fielmente a forma do hidrograma

Observa-se nesta Figura 19 que para alguns eventos ocorreram precipitações para as quais os picos de vazão específica são distintos dos produzidos pelo TOPMODEL. Estas diferenças implicam na redução do valor do coeficiente $\mathrm{E}$ calculado pelo modelo.

\section{SIMULAÇÃO}

Conhecidos os valores dos parâmetros podese aplicar o modelo para simular uma série de dados de vazões registradas entre 17/03 e 23/04 de 1995. Os dados abrangeram uma sequência total de 905 horas, havendo um período de 104 horas para o qual não se tinha registro de vazão e de precipitação. Esta foi considerada nula no período e os valores de vazão foram calculados com auxílio da curva chave, admitindo que no período o nível da água do rio variou linearmente. As Figuras 20 e 21 mostram os resultados para resoluções do MNT de 30 e 210 m respectivamente

Inicialmente deve-se notar nestas figuras que as vazões de pico calculadas pela modelo usando os parâmetros calibrados com eventos de 1988, são, em sua maioria, superiores às registradas na estação. As vazões de pico apresentaram valores crescentes com relação às resoluções espaciais do MNT, por exemplo, para tempo igual a $56 \mathrm{~h}$ foi observado um pico de vazão específica de $0,00032 \mathrm{~m} \cdot \mathrm{h}^{-1}$. O valor calculado para a grade de $30 \mathrm{~m}$ foi de $0,0003781 \mathrm{~m} \cdot \mathrm{h}^{-1}$, e para a de $210 \mathrm{~m}$ de $0,0004668 \mathrm{~m} \cdot \mathrm{h}^{-1}$. Para outros picos de vazão, este comportamento do modelo, se repete.

\section{CONCLUSÕES}

Neste trabalho foi aplicado o modelo chuvavazão TOPMODEL à bacia do rio Descoberto a montante do lago de mesmo nome, situada no Distrito Federal, com o objetivo de avaliar o desempenho 


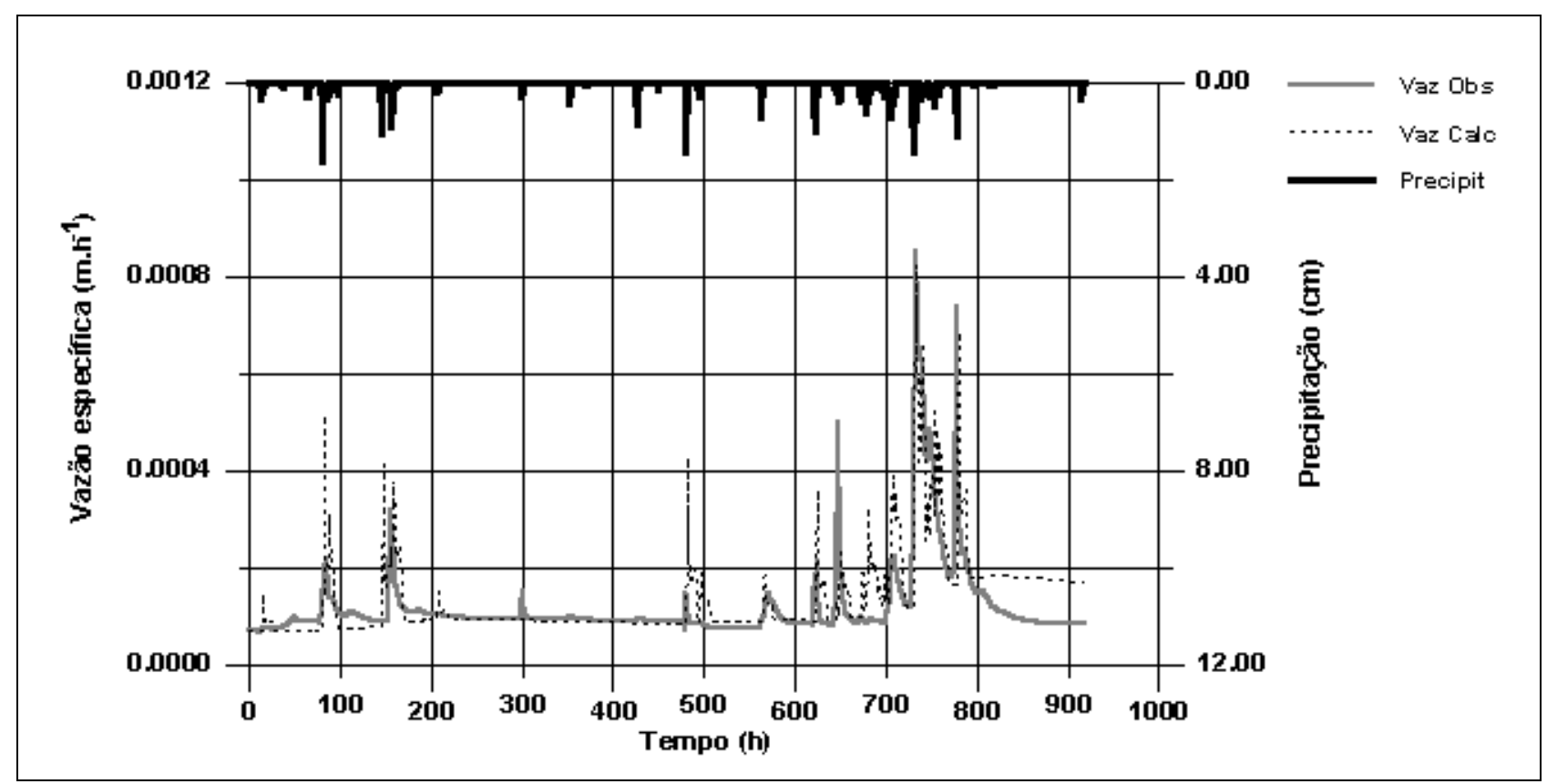

Figura 19. Simulação chuva-vazão - bacia rio Descoberto, 1988.

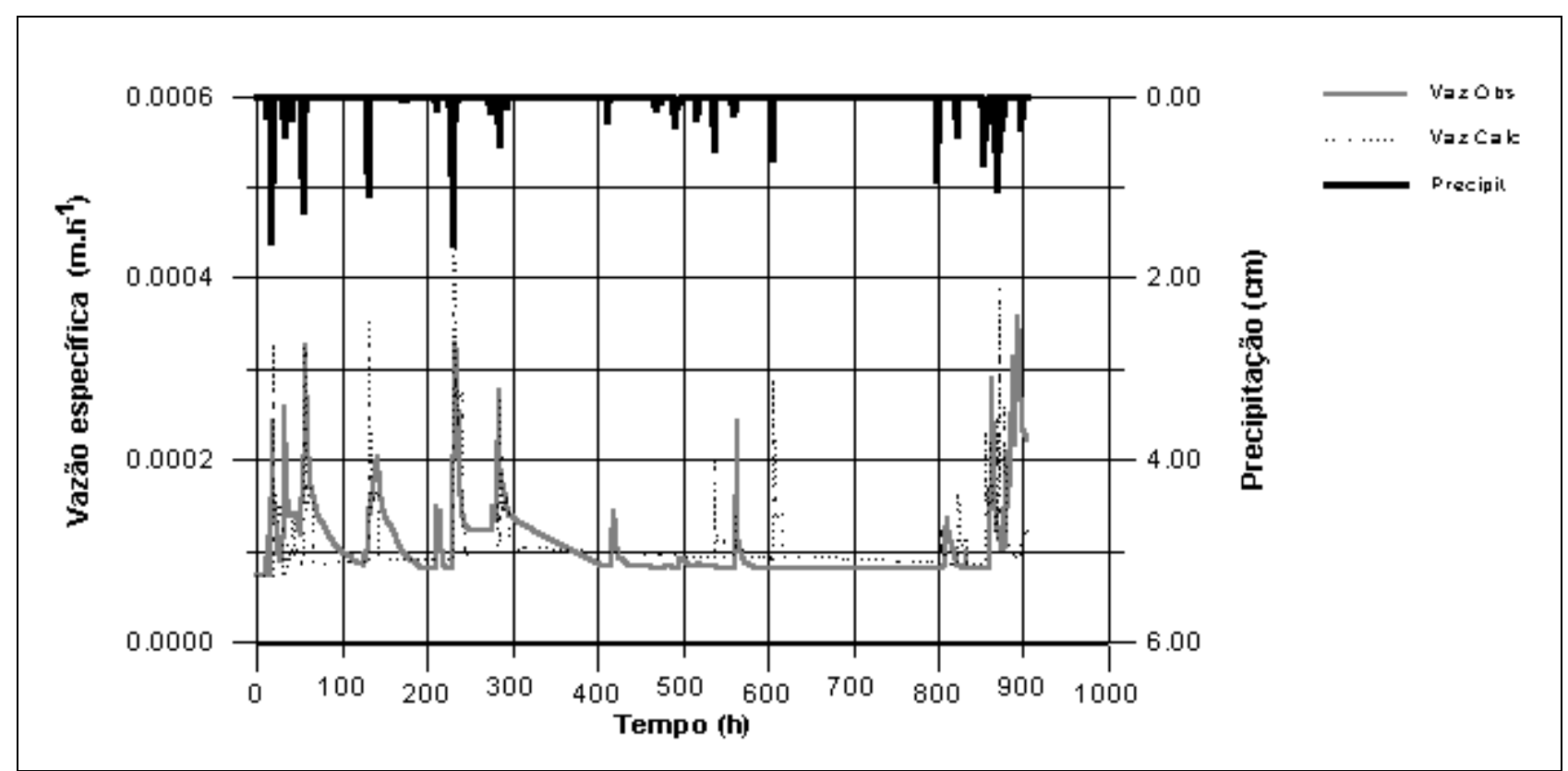

Figura 20. Simulação - bacia rio Descoberto, 1995 - resolução espacial do MNT: 30 m.

global do modelo, identificando as dificuldades na sua aplicação, além de aproveitar as potencialidade que as técnicas de geoprocessamento oferecem para aquisição e manipulação de dados e informações espaciais. Para tanto, foram feitos inicialmente estudos de sensibilidade do modelo aos vários parâmetros, identificando-se aqueles que mais influenciam nos valores das vazões calculadas.

A partir destas informações, o modelo foi calibrado, estimando-se os valores de todos os parâmetros, utilizando dados referentes a diversos eventos registrados no ano de 1988. Esta estimativa levou em consideração a resolução espacial do modelo numérico do terreno, obtendo-se um conjunto de valores dos parâmetros para cada uma das resoluções espaciais considerada. Finalmente o modelo foi aplicado com a intenção de verificar seu funcionamento, utilizando-se dados registrados em eventos ocorridos em 1995. 


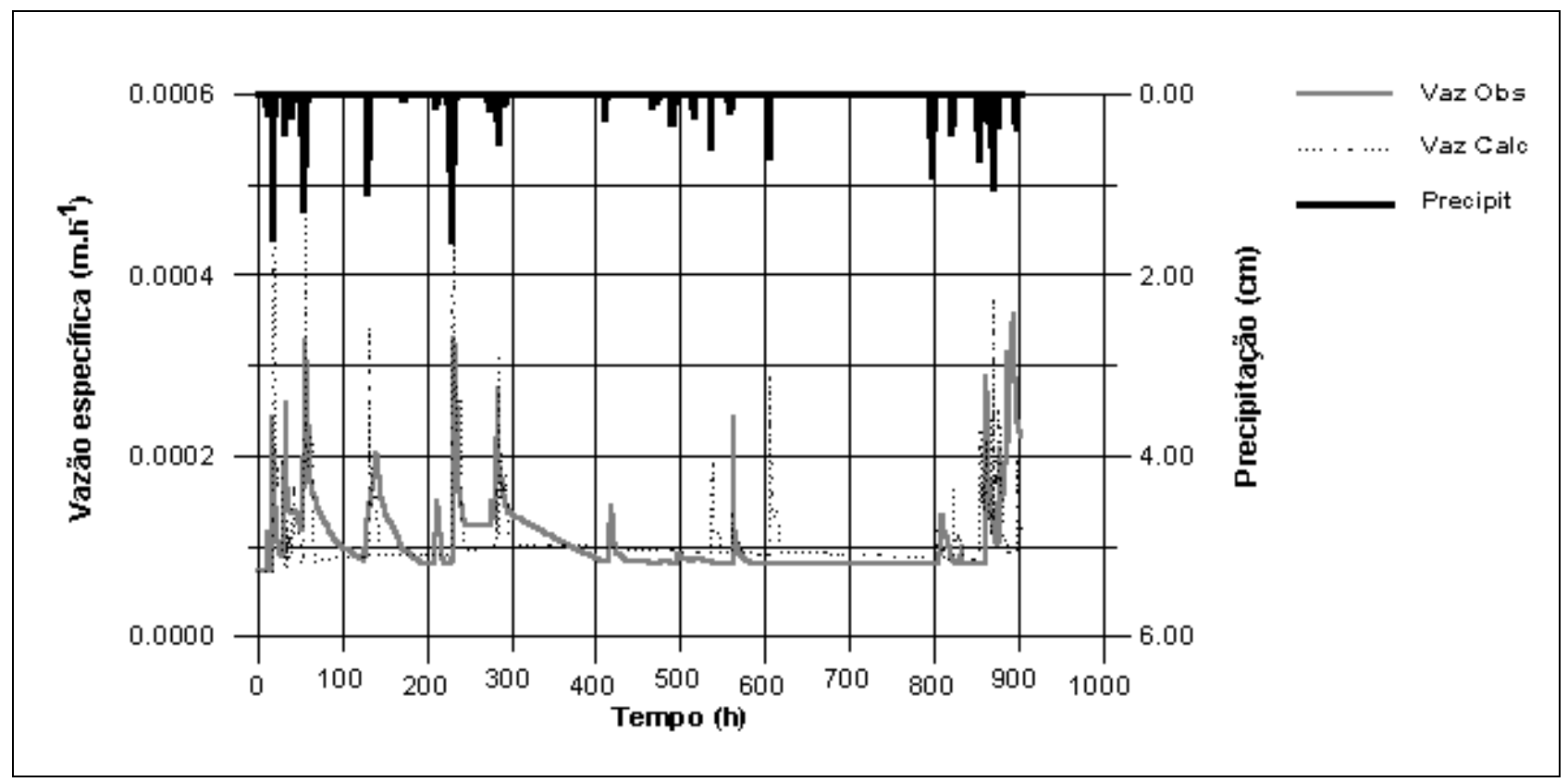

Figura 21. Simulação - bacia rio Descoberto, 1995 - resolução espacial do MNT: 210 m.

O modelo apresenta reduzida quantidade de parâmetros e poucos apresentam influências significativas nos resultados. Nesta aplicação do modelo, os parâmetros que mais influenciaram a forma e o valor de vazão de pico do hidrograma foram $T_{0}$ e $m$, enquanto que os parâmetros de velocidade $\mathrm{CHV}$ e RV alteraram principalmente o tempo ao pico. Como o número de parâmetros é pequeno, o trabalho de determinação de seus valores não apresentou dificuldades.

Os valores do parâmetro $\mathrm{m}$ determinados na calibração, apresentaram média de 0,15 m. Na utilização do modelo, $m$ foi aumentando para 0,18 m em função deste valor ter sido o que melhor representou o ramo recessivo do hidrograma, particularmente para os eventos de maior intensidade. Este valor de $\mathrm{m}$ é bastante alto quando comparado aos citados na bibliografia, 0,002 $\mathrm{m}$ no trabalho de Mine \& Clarke (1996), 0,032 $\mathrm{m}$ na bibliografia de referência do TOPMODEL Beven et al. (1994), $0,02 \mathrm{~m}$ aplicação do modelo feita por Saulnier (1996) e por Holko \& Lepistö (1997), sendo somente igualado como extremo superior da faixa de valores citada por Horneberger et al. (1985), aventando-se a possibilidade desta diferença ser originada pelas características dos solos da bacia estudada.

Dos parâmetros, $T_{0}$ foi o que apresentou maior variação de valores, havendo dependência em relação à resolução espacial do modelo numérico do terreno. Os valores deste parâmetro, obtidos para as maiores resoluções espaciais do MNT, foram os menores indicando que, para se atingir o objetivo dos parâmetros do modelo representarem propriedades físicas deve-se gerar o MNT com a maior resolução possível, para com isso obter a distribuição do índice topográfico que melhor descreva a topografia do terreno.

$\mathrm{Na}$ simulação aplicada à série contínua de dados (905 h) observados entre março e abril de 1995, utilizando no modelo valores dos parâmetros determinados para o ano de 1988, verificou-se um aumento dos picos de vazão específica. Para se diminuir as diferenças entre picos de vazão calculados e observados, foi necessário alterar os valores de $T_{0}$ conforme mostrado na Tabela 4.

Tabela 4. Valores de To estimados.

\begin{tabular}{ccc}
\hline $\begin{array}{c}\text { Resolução espacial } \\
(\mathrm{m})\end{array}$ & $\begin{array}{c}\frac{1988}{\ln \mathrm{T}_{0}} \\
\left(\mathrm{~m}^{2} \cdot \mathrm{h}^{-1}\right)\end{array}$ & $\begin{array}{c}\frac{1995}{\ln \mathrm{T}_{0}} \\
\left(\mathrm{~m}^{2} \cdot \mathrm{h}^{-1}\right)\end{array}$ \\
\hline 30 & 2,0 & 2,4 \\
90 & 3,4 & 4,2 \\
150 & 3,9 & 4,8 \\
210 & 4,1 & 4,9 \\
\hline
\end{tabular}

As correções dos valores do parâmetro $T_{0}$, apresentados nesta tabela, foram relativamente grandes para as menores resoluções espaciais do MNT, aproximadamente $90 \%$ para as maiores grades utilizadas neste estudo, $150 \mathrm{~m}$ e $210 \mathrm{~m}$, enquanto que para a maior resolução espacial 
empregada, grade com $30 \mathrm{~m}$ de lado, foi de aproximadamente $35 \%$.

Constata-se nos hidrogramas obtidos para o ano de 1995, para todas as resoluções espaciais do MNT, que os valores de vazão observados são menores que os calculados. Na utilização de água do rio para irrigação pode-se obter uma das possíveis explicações para a ocorrência de valores de vazões calculadas maiores que as observadas, embora não se disponha de informações para comprovar esta afirmação. O aumento de área cultivada foi verificado através da classificação das imagens do satélite Landsat-TM para os dois anos estudados, utilização esta que se verifica até o presente momento.

O aumento da área cultivada poderia indicar um aumento no fator utilizado no cálculo da evapotranspiração potencial, o que implicaria numa diminuição da vazão do rio. No entanto, a alteração no valor deste fator foi muito pequena, pois para a área de cerrado que foi transformada em área cultivada, assumiu-se o mesmo fator de conversão de evaporação para evapotranspiração que é a mesma classe de cobertura na qual as áreas cultivadas estão inseridas.

O índice, sugerido por Beven, para determinar a qualidade do ajuste, é o fator $E$. Mais do que um índice da qualidade global do ajuste, este fator quantifica o desvio entre as vazões calculadas e as observadas, representando a capacidade do modelo de reproduzir a forma do hidrograma. Nas diversas simulações realizadas, obteve-se ajustes razoavelmente precisos em termos de volume, vazão de pico e tempo de pico. No entanto, os valores de $E$ foram pequenos, indicando que $o$ modelo não conseguiu reproduzir fielmente a forma do hidrograma.

Desta forma, de acordo com os resultados obtidos, nesta aplicação à bacia do Rio Descoberto, esta versão do modelo seria mais apropriada para utilizações em estudos de enchentes, onde o interesse particular está na vazão de pico, tempo ao pico e volume total mais do que na forma do hidrograma.

É importante destacar que o TOPMODEL, embora concebido como semi-distribuído, apresenta algumas simplificações uma vez que determinados parâmetros e variáveis são assumidos como homogêneos em toda a bacia, como, por exemplo, as intensidades de evapotranspiração e precipitação. O cálculo da profundidade do lençol freático, que é usado na determinação das áreas onde ocorre saturação do solo, é feito de forma discretizada, considerando as áreas homogêneas que possuem o mesmo valor de índice topográfico. Desta forma pode-se dizer que o TOPMODEL é um modelo híbrido, podendo incorporar diferentes graus de discretização para variáveis e parâmetros.

Finalmente, deve-se ressaltar a importância de se ter uma maior atenção na determinação dos valores dos parâmetros $\mathrm{m} \mathrm{e}_{0}$, para os quais o modelo apresentou maior sensibilidade, em particular o parâmetro $\mathrm{T}_{0}$, que depende da resolução espacial do modelo numérico do terreno. Observouse, nas aplicações para épocas distintas, que as maiores resoluções do MNT influenciam em menor grau o valor do parâmetro $T_{0}$.

É também desejável que se trabalhe com a bacia de forma mais distribuída possível, dividindoa em sub-bacias que apresentem maior homogeneidade em termos de cobertura de solo, aprimorando assim os cálculos de evapotranspiração e infiltração e portanto, do balanço hídrico como um todo, podendo-se tira assim maior proveito das técnicas de geoprocessamento, melhorando o ajuste do hidrograma calculado ao observado.

\section{AGRADECIMENTOS}

O primeiro autor agradece à CAPES pelo fornecimento de bolsa de estudo.

\section{REFERÊNCIAS}

BEVEN, K. J. (1984) Infiltration into a class of vertically non-uniforrm soils. Hydrol. Sci. J., 29, p. 425-34.

BEVEN, K. J. (1986) Hillslope runoff processes and flood frequency characteristics. In: ABRAHAMS, A. D. (ed.) Hillslope Processes. Allen and Unwin, Boston, EUA, p. 187-202.

BEVEN, K. J.; QUINN, P.; ROMANOWICZ, R.; FREER, J.; FISHER, J.; LAMB, R. (1994) Topmodel and gridatb Distribution Programs - A users guide to the distribution versions (94.01). CRES Technical Technical Report TR110/94, Lancaster University, UK, p. 63.

FRANCHINI, M.; WENDLING, J.; OBLED, C.; TODINI, E. (1996) Physical interpretation and sensitivity analysis of the TOPMODEL. J. Hydrol., 175, p. 293-338.

HOLKO, L.; LEPISTÖ, A. (1997) Modelling the hydrological behaviour of a mountain catchment using TOPMODEL. J. Hydrol., 196, p. 361-77.

HORNBERGER, G. M.; BEVEN, K. J.; COSBY, B. J.; SAPPINGTON, D. E. (1985) Shenandoah watershed study: Calibration of a topographybased, variable contributing area hydrological model to a small forest catchment. Water Resour. Res., 21 (12), p. 1841-50.

KIRKBY, M. J. (1975) Hydrograph modelling strategies. In: Peel, R., Chisholm, M. e Haggett, P (eds). Process in Physical and Human Geography. Heinemann, p. 69-90. 
MINE, M. R. M.; CLARKE, R. T. (1996) O uso do TOPMODEL em condições brasileiras: Resultado preliminar. RBRH - Revista Brasileira de Recursos Hídricos, 1 (2), p. 89-105.

QUINN, P.; BEVEN, K. J.; CHEVALLIER, P.; PLANCHON, O. (1991) The prediction of hillslope flow paths for distributed hydrological modellimg using digital terrain models. Hydrological Processes, 5, p. 59-79.

SAULNIER, G. M. (1996) Information pedologique spatialisee et traitementes topographiques ameliores dans la modelisation hydrologique par TOPMODEL. Tese de Doutorado, Institut National Polytechnique de Grenoble, França, p. 318.

VARELLA, R. F. (1998) Simulação matemática do processo de transformação chuva em vazão: Estudo do modelo TOPMODEL. Dissertação de Mestrado - Universidade de Brasília. Faculdade de Tecnologia. Departamento de Engenharia Civil, p. 157.

\section{Mathematical Simulation of Rainfall- Flow Transformation. Study of the TOPMODEL}

\section{ABSTRACT}

The TOPMODEL (Topography Based Hydrological Model) is a rainfall-runoff model that utilizes a variable contributing area to estimate runoff production. The determining factors of its generation are represented by terrain topography and through an exponential function relating transmissivity and soil depth, measured from the surface of the terrain.

The influence of catchment topography is considered in the model through an index calculated from the digital terrain model (DTM). This study focuses mainly on the the analysis of the influence of the spatial resolution of the DTM in model's performance. For that, a catchment located in the Federal District was selected and seven DTMs with a spatial resolution of $30,60,90,120$, 150, 180 and $210 \mathrm{~m}$ were built. The corresponding distributions of the topography index were then calculated from the digital terrain models.

The results of model calibration and a sensitivity analysis are presented showing the influence of the main parameters on its performance.

Finally the results of the model application are shown emphasizing the main conditions that have to be observed in order to obtain good results. 